\title{
THE INTRODUCTION OF ROBOTIC TECHNOLOGY: PERCEPTIONS OF THE WORK FORCE OF AN AEROSPACE DEFENSE COMPANY
}

\section{DISSERTATION}

\author{
Presented to the Graduate Council of the \\ University of North Texas in Partial \\ Fulfillment of the Requirements
}

For the Degree of DOCTOR OF PHLOSOPHY By

William B. Rose, Jr., B.B.A., M.B.A.

Denton, Texas

August, 1988 
Rose, Jr., William B., The Introduction of Robotic Technology: Perceptions of the Work Force of an Aerospace Defense Company. Doctor of Philosophy (Management), August, 1988, 124 pp., 47 tables, bibliography, 91 titles.

This dissertation examines the effect that the introduction of an advanced manufacturing technology, specifically robotics, has on the work force of an aerospace defense company. In this endeavor, there are two main objectives. First, this study determines whether workers feel that their jobs are threatened by the introduction of robotic technology. Secondly, the research compares the degree to which workers from different labor types feel this threat.

A review of the literature reveals that the technical factors involving manufacturing technology have been thoroughly examined and discussed, but the effect that they have on the work force has been somewhat neglected. This dissertation develops ten hypotheses to ascertain the perceived threat to job security for workers within an aerospace defense company.

This study is based on an employee survey that examined the employee's perceived threat to job security by the introduction of robotics. The primary research was obtained from employees within an aerospace defense company through the use of questionnaires in a three phase approach. The first phase utilized a pretest that sampled the questionnaire prior to the company-wide solicitation. The second phase administered the questionnaire to the three labor types within 
the work force. Phase three consisted of data reduction and the comparison of the primary data to the research hypotheses.

The results of the study concluded that workers closer to the robotic technology (hands-on employees) felt more threatened about their job security than workers more removed from the technology (support personnel and management). It was further found that the hands-on workers felt that the major factor that lead to the introduction of robots was the desire to lower labor costs while support personnel and managers felt that the major factor that lead to the introduction of robots was due to increasing productivity. Additional hypotheses tested in this study include the effect that robots have on the perceptions of the work force toward the company's employment level, worker apprehension and reaction, training, safety, health, and competition. 


\section{PREFACE}

One of the unique aspects of the aerospace defense industry. is the dedication of large capital expenditures for relatively low production rate products. Traditionally, aerospace defense companies have used highly specialized tooling and equipment to manufacture those products. This approach is changing, however, and today, most aerospace defense companies are transitioning from the use of specialized plants producing specialized products toward flexible manufacturing which allows rapid changeover of products. Aerospace defense products readily align themselves with the flexible manufacturing approach because the roles of defense products are continuously evolving. Product evolution requires the capability to quickly redesign current products in order to meet these new and expanded roles.

The introduction of robotics was selected for this dissertation because the robot represents one area of advanced manufacturing technology that has shown advances in recent years and has been chosen by most manufacturing industries to play an integral role in their development of the "factory of the future." Complementary manufacturing technologies are also being purchased with robots in an effort to integrate a flexible manufacturing system. The aerospace defense company chosen for data accumulation has 
acquired several robots during recent years and plans to continue the procurement of robots during the next several years. 


\section{TABLE OF CONTENTS}

Page

PREFACE

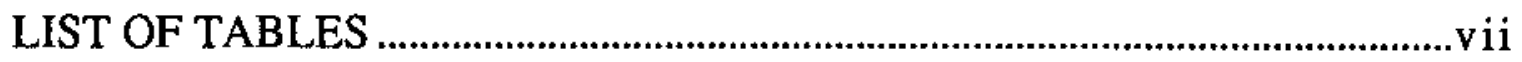

\section{CHAPTER}

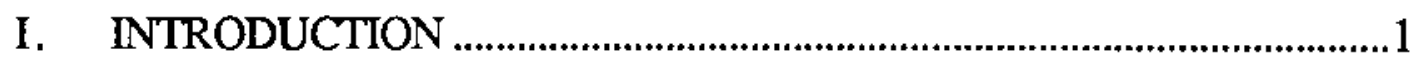

Statement of the Problem............................................................2

Purpose of the Research ...........................................................

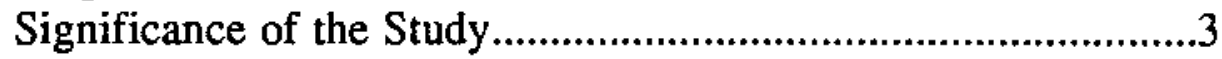

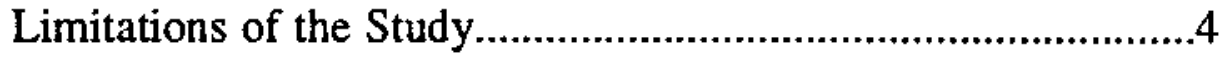

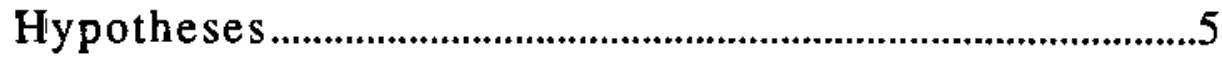

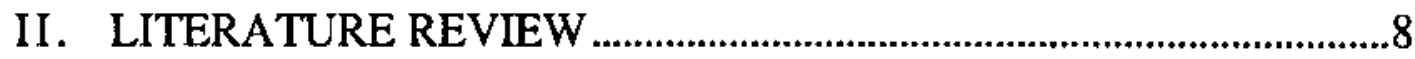

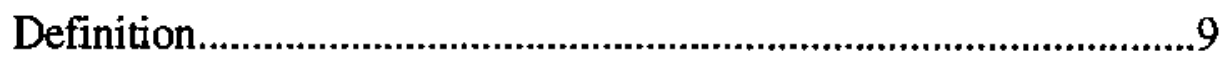

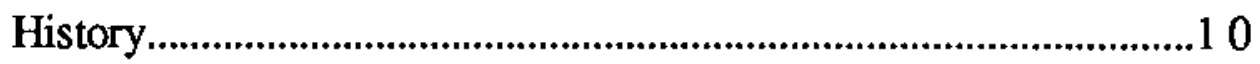

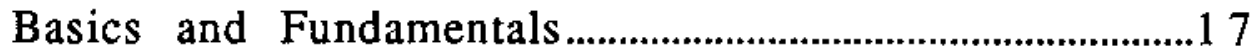

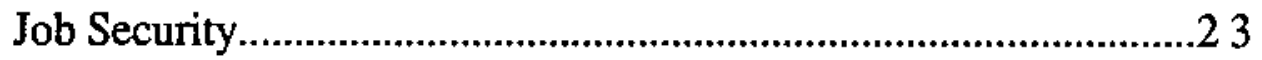

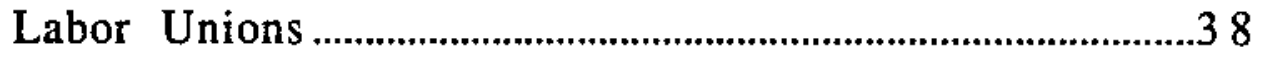

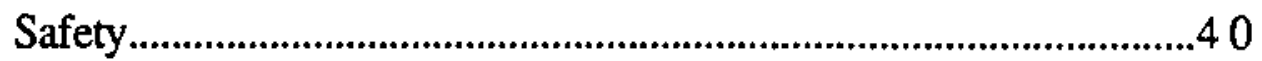

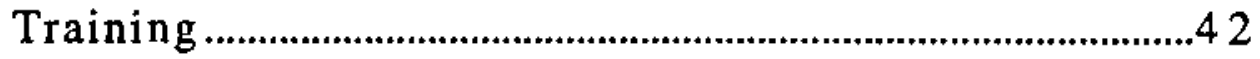

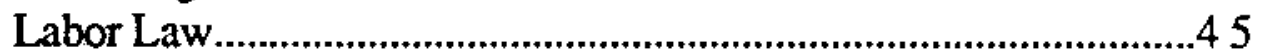

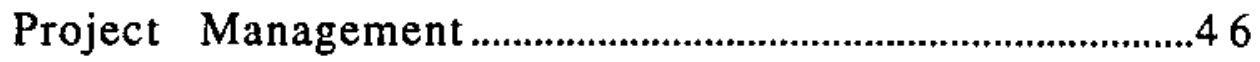

III. METHODOLOGY

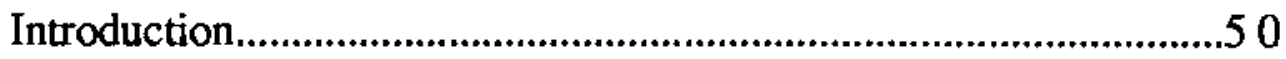

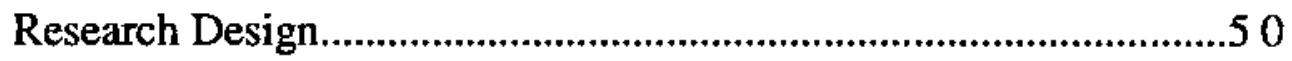

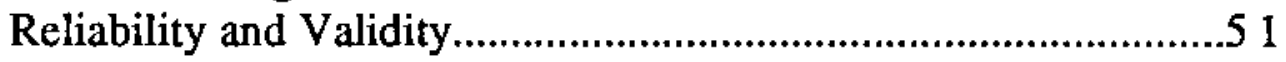

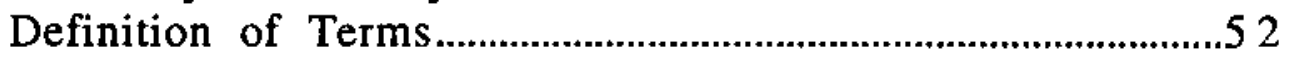

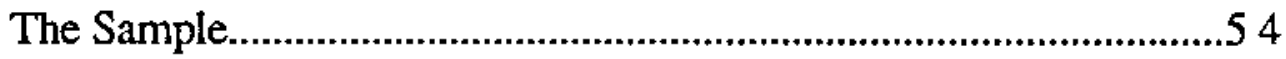

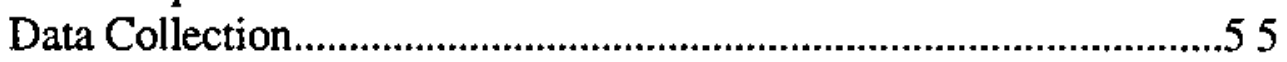

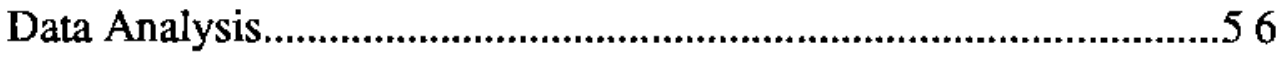




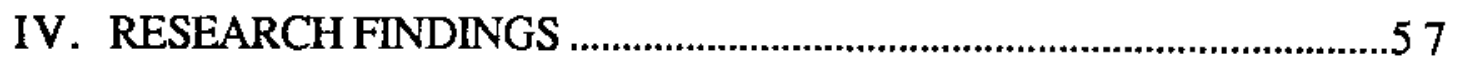

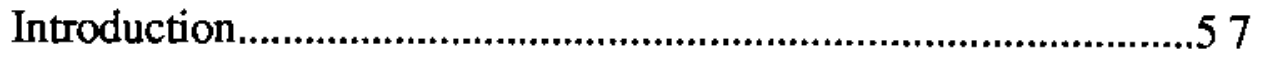

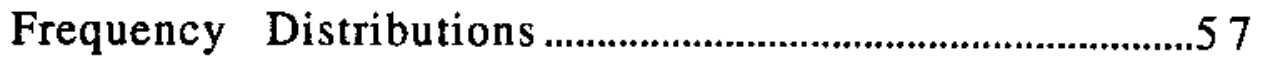

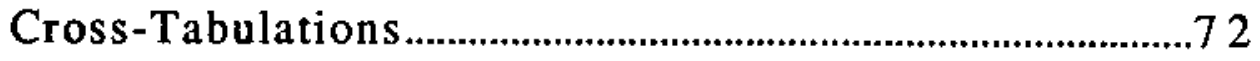

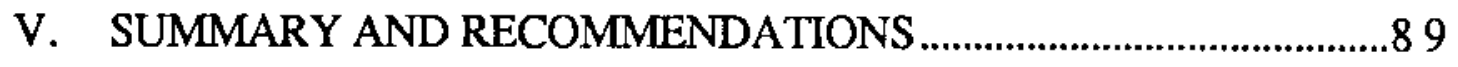

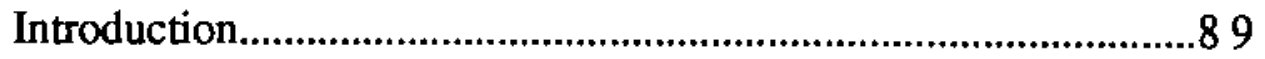

The Results of Hypothesis Testing .......................................89

Topics for Further Research..................................................99

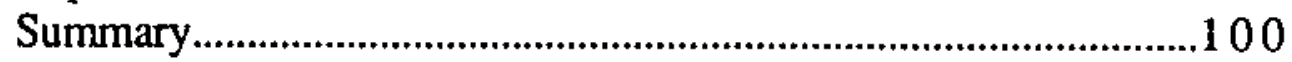

APPENDICES

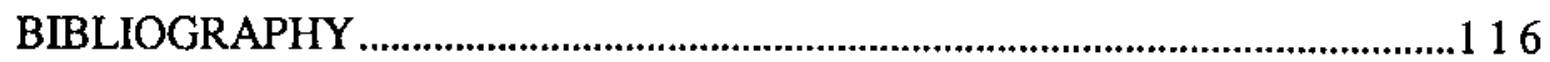




\section{LIST OF TABLES}

TABLE Page

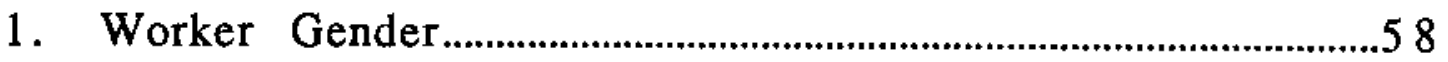

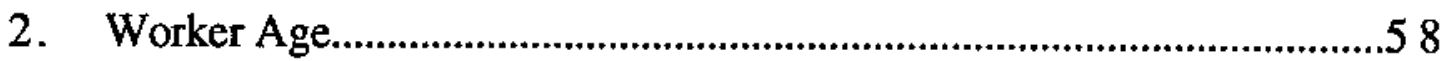

3. Years that Worker Has Been Employed with the Company.

4. Years that Worker Has Been at Present Position within the Company.

5. Current Labor Type of the Worker within the Company.

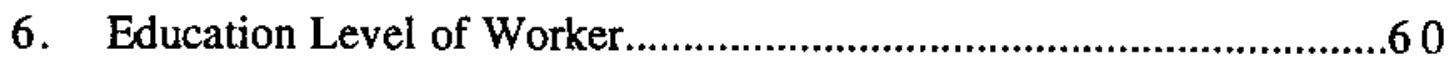

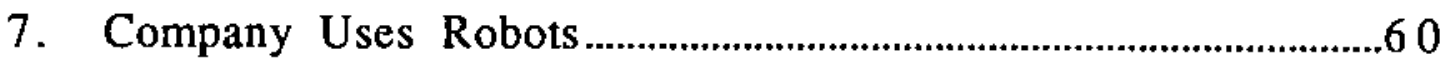

8. Threat to Worker Job Security ...................................................61

9. Threat to Co-worker's Job Security ............................................6 1

10. Belief of Worker as to the Major Factor for Robot Introduction.

11. Belief of Co-worker as to the Major Factor for Robot Introduction.

12. Opinion of Worker on the Effect of Robots to the Employment Level of the Company.

13. Opinion of Co-worker on the Effect of Robots to the Employment Level of the Company 
TABLE

14. Response of Worker to Statement Regarding Chronic Unemployment Among Displaced Workers Resulting from the Increased Usage of Robots

15. Co-workers Agree with Respondent to Statement Regarding Chronic Unemployment Among Displaced Workers Resulting from the Increased Usage of Robots

16. Reaction of Worker when Confronted with the Introduction of Robots

17. What Was Done to Reduce Worker Apprehension to Facilitate the Introduction of Robots

18. Opinion of Worker on Whether or Not the Company has a Policy of Retraining. Displaced Workers.

19. Opinion of Worker on Whether or Not the Policy Was Implemented

20. Opinion of Co-worker on Whether or Not the Company has a Policy of Retraining Displaced Workers.

21. Opinion of Co-worker on Whether or Not the Policy Was Implemented.

22. Degree of Responsibility the Individual Should Have in Retraining Due to Displacement By Robots.

23 Degree of Responsibility the Company Should Have in Retraining Employees Displaced By Robots.

24. Degree of Responsibility that Education Should Have in Retraining Employees Displaced By Robots.

25. Degree of Responsibility that Government Should Have in Retraining Employees Displaced By Robots 
26. Degree of Responsibility that Unions Should Have in Retraining Employees Displaced By Robots...............................7 0

27. Belief of Worker on Whether Robots Can Reduce the Safety and Health Hazards of a Company

28. Belief of Worker on Whether Robots Can Reduce the Safety and Health Hazards of Their Company

29. Belief of Worker on Whether Robots Can Make a Company More Competitive.

30. Belief of Worker on Whether Robots Can Make Their Company More Competitive

31. Cross-Tabulation of Question 5 to Question 8............................73

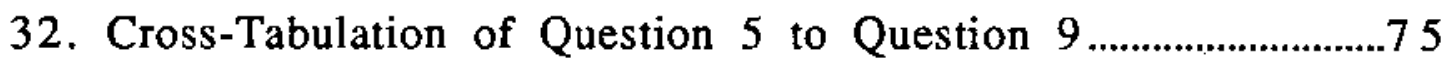

33. Cross-Tabulation of Question 5 to Question $10 \ldots \ldots \ldots \ldots \ldots \ldots \ldots . . . . . .76$

34. Cross-Tabulation of Question 5 to Question $11 \ldots \ldots \ldots \ldots \ldots \ldots \ldots \ldots . . . . . . . . . . .77$

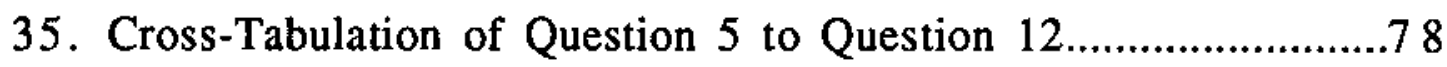

36. Cross-Tabulation of Question 5 to Question 13........................79

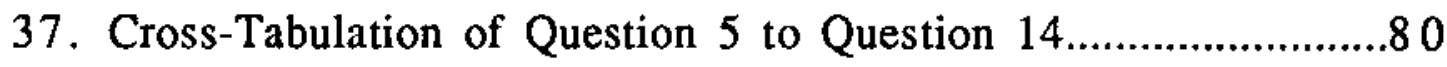

38. Cross-Tabulation of Question 5 to Question $15 \ldots \ldots \ldots \ldots \ldots \ldots \ldots . . . . . . . . . . . . .11$

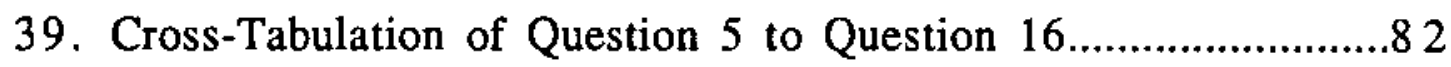

40. Cross-Tabulation of Question 5 to Question 17.......................83

41. Cross-Tabulation of Question 5 to Question 18........................... 44

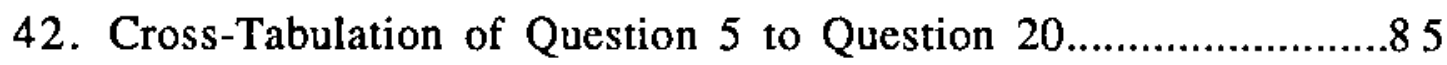


TABLE

43. Cross-Tabulation of Question 5 to Question 22.......................86

44. Cross-Tabulation of Question 5 to Question 24......................8 7

45. Cross-Tabulation of Question 5 to Question 25.......................8 7

46. Cross-Tabulation of Question 5 to Question 26.........................88

47. Comparison of Survey Results to Research Hypotheses........90 


\section{CHAPTER I}

\section{INTRODUCTION}

For the past several years, the United States government has been burdened with the need to be competitive with foreign nations in the production of low cost weapon systems. This problem of competitive pricing coupled with the political climate calling for a balanced national budget has pushed the acquisition agency of the Department of Defense into a precarious situation. As with other industries, the defense industry believes that one solution to the challenge of these conflicting objectives rests with the development and introduction of new manufacturing technologies.

Aerospace is one of the major areas within the defense industry impacted by the introduction of advanced manufacturing technology. There are two major drivers in the implementation of new manufacturing technologies into this industry. The first is the desire to provide sophisticated weaponry, requiring the development of new materials. In order to produce these materials, it is necessary to implement new manufacturing technologies. The second driver is the need to manufacture products at reduced costs which cannot be realized by current practices.

In the desire to implement these new technologies, it should be recognized that the aerospace defense industry is a capital intensive industry and competes in capital intensive markets even though relatively large numbers of people traditionally are employed. A 
major problem with the introduction of new manufacturing technology is the need for quantitative analysis and analytical approaches to solicit management approval for large amounts of capital resources. There are several methodologies such as return on investment (ROI), net present value (NPV), and others that can and do satisfy the requirements of management to determine the attractiveness of one investment over another. Even so, the acquisition of capital intensive equipment is viewed by the aerospace industry as a highly complex and uncertain activity based on the assumptions included in the quantitative analysis.

A frequently overlooked factor involved in the acquisition and implementation of robots is the complexity and diversity of the human resource factor. The human resource factor in the aerospace defense industry traditionally has been largely based on qualitative methods to determine the ability of the work force to deal effectively with the severity and swiftness of change. In the acquisition of new manufacturing technology, the anticipated reaction of the existing work force should be examined to ascertain the likelihood of successful implementation. The struggle between the challenge to survive presented by the external pressure of competition and the internal workings of any company in the aerospace defense industry should be a concern to all organizations interested in the introduction of new manufacturing technologies.

Statement of the Problem

The introduction of advanced manufacturing technology into the work environment affects several facets within an organization. 
Technical factors that involve manufacturing technology have been 3 thoroughly examined and discussed in the literature, but the effect that they have on the work force has been somewhat neglected. The introduction of advanced manufacturing technologies and the effect of robotics on the work force is the focus of this study.

\section{Purpose of the Research}

The purpose of this dissertation is to examine the effect that the introduction of an advanced manufacturing technology, specifically robotics, has on the work force of an aerospace defense company. In this endeavor, there are two main objectives. First, this study will determine if workers feel that their jobs are threatened by the introduction of robotic technology. Secondly, the research will compare the degree to which workers from different labor types feel this threat. The objective of this study is to aid in the understanding of the differences in worker attitudes concerning manufacturing technology and assist in future applications of such into the workplace.

\section{Significance of the Study}

As will be shown in the literature survey, the studies and forecasts regarding the impact of robotics is inconsistent and confusing. It is the intent of this dissertation to provide a better understanding of the impacts of robotics on the work force and the reaction of employees in three separate labor types (hands-on operator, support personnel, and management) within one aerospace defense company. The understanding of these attitudes toward 
advanced manufacturing technologies and robotics in particular are invaluable to those interested in their successful introduction. It is for this reason that the study of worker attitudes toward robotics gives this dissertation significance.

\section{Limitations of the Study}

The discussion of this paper is meaningful where the introduction of advanced manufacturing technologies, and specifically that of robotics, is coupled with the aerospace defense industry. The structure of this paper was chosen to better orient the reader with the knowledge of manufacturing technology and specifically robotics.

The primary research population is confined to one aerospace defense company for three reasons. First, the decision to limit this study to a single aerospace defense company was to gain insight into the depth of the work force that would not be feasible at the industry level in both time and expense. Secondly, many aerospace defense companies claim that information regarding manufacturing technology is proprietary, making such data difficult to obtain. And lastly, the subject of job security involving robotic technology is viewed as sensitive to the work force and therefore requires a low profile examination. The identity of the aerospace defense company chosen is not disclosed because of the sensitivity and proprietary nature of this study. 
The following hypotheses will be tested in order to achieve the purposes of this research.

1. $\mathrm{H}_{0}=\mathrm{Job}$ security is highest for employees who are furthermost from the robotic technology (support personnel and management), with such security decreasing as workers are brought into closer contact with robots (hands-on).

$\mathrm{H}_{1}=$ There is no difference between labor types.

2. $\mathrm{H}_{0}=$ Workers closer to the robotic technology (hands-on) perceive that the lowering of labor costs is the major factor prompting the introduction of robotics into their company while workers more removed from robotics (support personnel and management) believe other factors are more important.

H1 = There is no difference between labor types.

3. $\mathrm{H}_{0}=$ Workers closer to the robotic technology (hands-on) perceive that robots have decreased the employment level in their company while workers more removed from robotics (support personnel and management) believe that employment within their company has not changed or has even increased.

$\mathrm{H}_{1}=$ There is no difference between labor types.

4. $\mathrm{H}_{0}=$ Workers closer to the robotic technology (hands-on) agree that the increased usage of robots will cause chronic unemployment while workers more removed from robotics (support personnel and management) 
disagree that robotics applications will result in chronic ${ }^{6}$ unemployment.

$\mathrm{H}_{1}=$ There is no difference between labor types.

5. $\mathrm{Ho}=$ Workers closer to the robotic technology (hands-on) perceive that the reaction of employees to robots is negative or strongly negative while workers more removed from robotics (support personnel and management) believe that employee reaction to robots is positive or very positive.

H1 = There is no difference between labor types.

6. $\mathrm{H}_{0}=$ Workers closer to the robotic technology (hands-on) perceive that there was no effort to reduce worker apprehension to the introduction of robots while workers more removed from robotics (support personnel and management) believe that several methods were used. $\mathrm{H}_{1}=$ There is no difference between labor types.

7. $\mathrm{H}_{0}=$ Workers closer to the robotic technology (hands-on) perceive that the firm has no retraining policy with regard to the implementation of robots while workers more removed from robotics (support personnel and management) believe that such a policy exists. $\mathrm{H}_{1}$ = There is no difference between labor types.

8. $\mathrm{Ho}=$ Workers closer to the robotic technology (hands-on) believe that the union should have a larger degree of responsibility in training employees displaced by robots while workers more removed from robotics (support 
personnel and management) believe that unions should 7 not.

$\mathrm{H} 1$ = There is no difference between labor types.

9. $\mathrm{H}_{0}=$ Workers closer to the robotic technology (hands-on) believe that robots do not reduce the safety and health hazards while workers more removed from robotics (support personnel and management) believe that they do.

$\mathrm{H}_{1}=$ There is no difference between labor types.

10. $\mathrm{H}_{0}=$ Workers closer to the robotic technology (hands-on) believe that robots do not make the firm more competitive while workers more removed from robotics (support personnel and management) believe that they do.

$\mathrm{H} 1$ = There is no difference between labor types. 


\section{CHAPTER II}

\section{LITERATURE REVIEW}

The sources of data used in this survey were obtained from trade and management journals, books, trade shows, seminars, onsite observations, and films dealing with advanced manufacturing technologies. The focus of this literature survey was to analyze worker attitudes on the introduction of manufacturing technology and particularly robotics. This survey looks at both the positive and negative aspects of introducing advanced manufacturing technologies as seen from the human resource point of view.

The major headings for this literature survey were drawn from the main structures utilized in the literature. The headings were arranged in an order that could be followed logically in this chapter.

The first subject introduced in this chapter is the definition of the manufacturing technology designated by the term "robot", followed by their historical implications in order to gain insight as to the dilemmas that organizations face today. These two sections are followed by a summary of the basics and fundamentals of robotics. The major section of this literature survey focuses on the human factors, addressing job security, labor unions, safety, training, labor law, and project management. 


\section{Definition}

In order to examine robotics, it is necessary to discuss the definitions given to such devices. From the available literature, the definition differs depending on the country and application where the technology is used. The definition is extremely important when conducting an examination of the number of robots in use now or forecasted for the future. ${ }^{1}$ For example, the Japanese have defined a wide range of fairly unsophisticated machines as robots. ${ }^{2}$

In the United States, the term "robot" has been defined in the following ways: a multi-access, programmable manipulator that can do useful work automatically without human assistance; 3 a manufactured apparatus that has a humanoid appearance and exercises human-like functions well enough to be considered human in a given context; 4 a machine in the form of a human being that performs the mechanical functions of a human being; a

1 William C. Byham, "HRD and the Steel-Collar Worker," Training (January 1984): 59.

2 George Bickerstaffe, "Robotics: Managing the Change in Manufacturing," International Management (March 1983): 23.

3 Byham, "HRD and the Steel-Collar Worker," 59.

4 Emily Calis and Jeffrey G. Croll, "Robotics and Human Resource Development," in Robots 9 Conference Proceedings Held in Detroit. Michigan 2-6 June. 1985, (Privately Printed, 1985), 31.

5 Terry L. Leap and Allayne B. Pizzolatto, "Robotics Technology: The Implications for Collective Bargaining and Labor Law," Labor Law Journal (November 1983): 697. 
reprogrammable, multi-functional manipulator; 6 a computercontrolled machine of specialist design; ${ }^{7}$ a programmable, multifunctional device, designed to both manipulate and transport tools, parts or special manufacturing implements through variable programmed paths for the performance of specific manufacturing tasks; ${ }^{8}$ and a machine that can sense, think, and act in repeatable cycles. ${ }^{9}$ The definition used for this paper, unless stated otherwise, is the definition adopted by the Robot Institute of America. This definition is as follows: "A robot is a reprogrammable multifunctional manipulator designed to move material, parts, tools, or specialized devices through variable programmed motions for the performance of a variety of tasks." 10

\section{History}

The term "robot" comes from the Czech word "robotnik" which means worker, first introduced by the Czechoslovakian playwright

6 Fred K. Foulkes and Jeffrey L. Hirsch, "People Make Robots Work," Harvard Business Review (January-February 1984): 96.

7 Ewart Woolley, "Robots, Automation, and Spray Painting," Industrial Management and Data Systems (September-October 1983): 7.

8 Ron Zemke, "The Robots Are Coming! Training Tomorrow's High Tech Workers," Training (June 1983): 18.

9 Linda Argote and Others, "The Human Side of Robotics: How Workers React to a Robot," Sloan Management Review (Spring 1983): 31.

10 Charles J. Hollon and George N. Rogol, "How Robotization Affects People," Business Horizons (May-June 1985): 76; Colin Nomnan, "The New Industrial Revolution," Euturist (February 1981): 35. 
Karel Capek in his play R.U.R. (Rossum's Universal Robots) in 1921.11

In this play, robots were invented to save people from work, but instead of helping individuals, the robots killed them. ${ }^{12}$ In the 1940s, author Isaac Asimov portrayed robots in a more positive manner by showing them as friendly and helpful to humans. 13 Asimov created three laws in the programming of robots which are as follows: (1) A robot may not injure a human being or through inaction, allow a human to be harmed. (2) A robot may obey orders given by humans except when that conflicts with the first law. (3) A robot must protect its own existence unless that conflicts with the first or second laws. 14

The first robot mechanisms were developed in 1929 which lead to the first industrial robots, simple "pick and place" robots developed by the Planet Corporation in 1959.15 The first true founders of the modern robotic movement were George Devol and Joseph Engelberger. Devol founded the Unimation Corporation in 1958 and was joined by Engelberger to manufacture the company's

11 Calis and Croll, "Robotics and Human Resource Development," 31; Dale McConkey and F. D. Barrett, "Managing in the Age the Robot," Business Quarterly (Winter 1982): 41.

12 Calis and Croll, "Robotics and Human Resource Development," 31.

13 Joseph F. Engelberger, Robots in Practice (New York: AMACOM, 1980), 3.

14 Ibid.

15 Calis and Croll, "Robotics and Human Resource Development," 32. 
first robot in 1961.16 It was the philosophy of using reprogrammable capabilities to prevent fast obsolescence that provided their robot with an advantage over typical industrial machinery. 17

The present robot manufacturing industry is in a state of transition with about two hundred manufacturers world-wide but with approximately twenty manufacturers dominating the market.18 The two oldest and largest robot producers in the United States are Cincinnati Milacron and Unimation Incorporated. Other robot producers include American Can, American Robot Corporation, Automatix Incorporated, Bendix, GCA, IBM, Prab Robots, Ransburg, Texas Instruments, Textron, Union Carbide, and United Technologies. 19 Robots are produced world-wide but the major foreign exporters of robots are Renault in France, Olivetti C.N. SpA and D.E.A. SpA in Italy, Dainichi Kiko, Fujitsu Limited, Hitachi Limited, Komatsu, Mitsubishi Corporation, Oril Corporation, Suzomo

16 Ibid.

17 Calis and Croll, "Robotics and Human Resource Development," 32; Sar A. Levitan and Clifford M. Johnson, "The Future of Work: Does it Belong to Us or to the Robots?" Monthly Labor Review (September 1982): 11.

18 Bickerstaffe, "Robotics: Managing the Change in Manufacturing," 23; Robert C. Longmire, "Robots are Joining the Work Force," Production and Inventory Management Review and APICS News (October 1982): 55.

19 Foulkes and Hirsch, "People Make Robots Work," 99. 
Machinery Works, Toshiba Corporation, and Yaskang Electric from Japan, ASEA AB in Sweden, and Volkswagen in West Germany. ${ }^{20}$

The number of robots in the United States has increased dramatically over the last twelve years: from 1,200 units in 1974 and 4,700 units in 198021 to over 25,000 units in 1987.22 It is predicted that by 1990 the number of robots in the United States will increase between 95,000 and 150,000 units. ${ }^{23}$ It is also predicted that the number of sales world-wide will increase from 100 million dollars in 1980 and 230 million dollars in 1982 to 2 billion dollars in 1990.24 One study asserts that the current generation of robots could currently perform seven million jobs and, even though it does not expect introduction at this rate, predicts that by 1990 it will be technically possible to replace all manufacturing

20 Ibid.

21 Byham, "HRD and the Steel-Collar Worker," 59; Calis and Croll, "Robotics and Human Resource Development," 35; Foulkes. and Hirsch, "People Make Robots Work," 94; Dave Lindorff, "Marketing Forecast, The Robot Revolution," Madison Avenue (February 1984): 39.

22 Bill Tanner, "What Every Senior Manager Should Know About Robotics," Robotics World (July 19, 1987): 26.

23 Calis and Croll, "Robotics and Human Resource Development," 35; Foulkes and Hirsch, "People Make Robots Work," 102.

24 Calis and Croll, "Robotics and Human Resource Development," 35; Foulkes and Hirsch, "People Make Robots Work," 99; Levitan and Johnson, "The Future of Work: Does it Belong to Us or to the Robots?", 11; Longmire, "Robots are Joining the Work Force," 54. 
workers in the automotive, electrical-equipment, machinery, and fabricated metals industries. 25

In addition to manufacturing, there are opportunities for robots in other fields such as pharmacy inventory control, service station operations, subway and hotel cleaning, hospital operations, household uses, space station operations, security and undersea exploration. ${ }^{26}$ Robots are also currently performing work that would normally be impossible such as the splitting of genes. 27

There are several reasons for the forecasted increase in robotics in the United States. As discussed below, these reasons include emphasis on rising labor costs, productivity, technological improvements in robotic capabilities, and the cost improvements of robots. ${ }^{28}$ It has been forecasted by many experts that the full impact and benefit of robots will not be realized this decade. 29

It was estimated that in 1980 the cost of an average present generation robot was only 3.1 times more than an average worker's

25 Levitan and Johnson, "The Future of Work: Does it Belong to Us or to the Robots?", 11.

26 Philip Burgert, "Robot Makers Looking for Better Markets," Manufacturing Week (May 1987): 5.

27 Marilyn Chase, "Robot Apprentices," The Wall Street Journal (10 November 1986): 18.

28 Argote and Others, "The Human Side of Robotics: How Workers React to a Robot," 31; Calis and Croll, "Robotics and Human Resource Development," 31; Edward M. Knod, Jr. and Others, "Robotics: Challenge for the Human Resources Manager, Business Horizons (March-April): 38.

29 Bickerstaffe, "Robotics: Managing the Change in Manufacturing," 24. 
annual wage, down from 10.5 times in 1971 and 4.3 times in 1976.30 Robots currently cost companies approximately six dollars per hour to operate while workers currently cost approximately twenty dollars an hour in both wages and benefits. ${ }^{31}$ An interesting note is that the cost of components used to manufacture robots is expected to decrease in the future while the average cost of wages for workers is expected to increase. 32

The cost of robots varies depending on the robotic package and options included. Simple industrial robots cost approximately 5,000 dollars while the more sophisticated robots might cost more than 100,000 dollars. ${ }^{33}$ It is estimated that in most cases a robot will pay for itself within two years of installation. 34

30 Ibid., 23.

31 Calis and Croll, "Robotics and Human Resource Development," 33; Albert C. Smith, Ir., "Robotics: A Strategic Issue," SAM Advanced Management Lournal (Spring 1985): 7.

32 Knod, Jr. and Others, "Robotics: Challenge for the Human Resources Manager," 39; Levitan and Johnson, "The Future of Work: Does it Belong to Us
or to the Robots?", 11.

33 Knod, Jr. and Others, "Robotics: Challenge for the Human Resources Manager," 39; Tanner, "What Every Senior Manager Should Know About Robotics," 27.

34 Knod, Jr, and Others, "Robotics: Challenge for the Human Resources Manager," 39; Leap and Pizzolatto, "Robotics Technology: The Implications for Collective Bargaining and Labor Law," 698; Lindorff, "Marketing Forecast, The
Robot Revolution," 42. 
It has also been demonstrated from historic data that robots boost productivity by twenty to thirty percent, 35 but as in any investment, it is important to match the correct robot with investment funds in order to yield high productivity. 36 Additionally, productivity is expected to increase as more computers are successfully interfaced with robotic technology. 37

A study of the accumulated productivity gains between the years 1970-1977 showed that Japan, Germany, and France experienced gains of 105 percent, 66 percent, and 54 percent respectively, while the United States showed a gain of only 26 percent. 38 The increases in Japan's economic and industrial strength was reportedly due to the productivity increases by the introduction of industrial robots. ${ }^{39}$ The Japanese also predict an estimated 2,900 percent increase in productivity in certain applications. 40

Argote, Goodman, and Schkade studied the attitudes of approximately thirty-seven blue-collar workers and thirty

35 Zemke, "The Robots Are Coming! Training Tomorrow's High Tech Workers," 25 .

36 Amal Nag, "Tricky Technology: Auto Makers Discover 'Factory of the Future' is Headache Just Now," The Wall Street Joumal, 13 May 1986, 1.

37 Calis and Croll, "Robotics and Human Resource Development," 33.

38 Ibid., 34.

39 Ibid.

40 Calis and Croll, "Robotics and Human Resource Development," 33; Smith, Jr., "Robotics: A Strategic Issue," 8. 
supervisors before and after the first installation of a robot. 41 Overall, the study found that there was a positive attitude toward the robot, but as workers acquired more experience, their beliefs that robots would increase productivity, decrease costs, and improve quality became more pessimistic. However, it was recognized by the team that the research was based on only one robot and it was the first installation of a robot into that company.

An additional benefit to be derived in the introduction of robotics is improved quality. 42 The introduction of numerically controlled tools and computer controlled robots have made improved quality and flexibility a reality. 43

\section{Basics and Fundamentals}

The robot is just one component of an overall flexible manufacturing system. The flexible approach integrates various manufacturing technologies into a unified production system in order to manufacture economically viable production volumes of a variety of parts. 44 Some managers view the introduction of robotics as a

41 Argote and Others, "The Human Side of Robotics: How Workers React to a Robot," 31-41.

42 Calis and Croll, "Robotics and Human Resource Development," 33; Foulkes and Hirsch, "People Make Robots Work," 96.

43 Bruce D. Henderson, "The Logic of Kanban," The Journal of Business Strategy (Winter 1986): 11.

44 David M. Dilts and Grant W. Russell, "Accounting for the Factory of the Future," Management Accounting (April 1985): 34; John I. Jarosh, "Prescription for Robotic Success: Right Job, Right Robot," Production (November 1985): 68; Knod, Jr. and Others, "Robotics: Challenge for the Human 
key part of ongoing automation and flexible manufacturing. ${ }^{45}$ This flexible manufacturing system utilizes a collection of automated production processes which may consist of a material transport system such as a robot and a system controller to manufacture a variety of products in low-volume batches. 46 A system controller performs tasks such as scheduling, specifying the operation order, identifying the machine to be used, verifying quality, and providing information to the user. ${ }^{47}$ The products in a flexible manufacturing system must share certain characteristics that allow the grouping in a particular part family such as size, material, or operation needed to be performed.48 The producers of manufacturing equipment are planning to provide complete flexible manufacturing systems in the future with the robot being the core ${ }^{49}$ It is predicted that the effectiveness of the robotic component will determine whether or not flexible manufacturing will be cost effective. 50

Resources Manager," 38; S. D.Saleh and Siva Pal, "Robotic Technology and Its Impact on Work Design and the Quality of Working Life," Industrial Management (May-June 1985): 1 .

45 Foulkes and Hirsch, "People Make Robots Work," 100; Lindorff, "Marketing Forecast, The Robot Revolution," 38.

46 Dilts and Russell, "Accounting for the Factory of the Future," 35; Lindorff, "Marketing Forecast, The Robot Revolution," 42.

47 Dilts and Russell, "Accounting for the Factory of the Future," 35. 48 Ibid.

49 Bickerstaffe, "Robotics: Managing the Change in Manufacturing," 23.

50 Lindorff, "Marketing Forecast, The Robot Revolution," 39. 
Robots have the capability of performing a wide variety of tasks associated with part and tool handling. 51 Robots are available in a wide range of configurations in order to perform a wide range of capabilities. According to Tanner, robots commonly consist of several similar major components: the manipulator, the controller, and the power supply.52 The manipulator is a series of linkages and joints which are capable of movement in various directions. These components actually perform the mechanical functions of the robot. These linkages may be coupled directly or driven through gears and are driven by actuators which may be pneumatic or hydraulic cylinders, hydraulic rotary actuators, or electric motors. The controller's function is to initiate and terminate the motions of the robot, to store the position and sequence data, and to interface with the operator. The complexity and sophistication of the controller enhances the ability of the robot. The function of the robot's power supply is to provide electrical, pneumatic, or hydraulic power to the robot for the performance of the activity desired.

There are several descriptions for the various configurations of robots available and although a variety of configurations exist, the basic robots are described as cylindrical, spherical, or jointedspherical, depending on their coordinate systems. 53 The cyclindrical 26.

51 Tanner, "What Every Senior Manager Should Know About Robotics,"

52 William R. Tanner, "Basics of Robotics," Industrial Robots (1981): 3.

53 Ibid., 4. 
coordinate robot consists of a horizontal arm mounted on a vertical column which has a rotating base. In this manner, the arm moves in and out while the carriage moves up and down on a rotating base depicting the working envelope as a portion of a cylinder. A spherical coordinate system consists of a horizontal arm which moves in and out, pivots on a vertical plane, and rotates in a horizontal plane about the base approximating a portion of a sphere as the working envelope. A jointed-spherical or jointed arm configuration consists of an upper arm and forearm joined by an elbow joint which allows movement in a vertical plane. The arm is attached to the trunk by a shoulder joint which allows rotary motion in a horizontal plane. This configuration approximates a portion of a sphere in the work envelope.

Three additional axes or "degrees of freedom" that enable a robot to perform it's function are dependent on the type and design of the wrist. The three main axes of a wrist are pitch, roll, and yaw. Pitch is the rotation in a vertical plane through the arm, roll is the rotation in a plane perpendicular to the end of the arm, and yaw is the rotation in a horizontal plane through the arm. By mounting a robot to a two-axis track on the floor or overhead, additional axes may be obtained. Depending on the needs of the user, a robot can provide as few as two and as many as seven or eight degrees of freedom.

On the last axis or wrist of the robot is a surface for the attachment of tools or "end effectors" with which the robot can 
perform it's functions. These devices can be unique to the application and, as such, are provided by the user. They are as varied as the robots they serve in order to perform various functions required by the operator.

Robots are generally classified as servo controlled devices which can be commanded to stop anywhere within the limits of travel, or non-servo controlled devices which move until the limits of travel are reached. A robot may be classified by the degrees of freedom in the robot's motion, through the method of articulation, through the control of motion, and through the method of activation.54 Even though robots vary greatly in complexity and capability, all robots share some common characteristics and the more flexible and universal the application, the more complex the robot will become. 55

In the acquisition of an industrial robot, several robotic characteristics such as modularity, configurability, quality mechanical components, mountings, motors, repeatability, serviceability, and safety should be considered.56 A robot must be able to perform a variety of tasks, demonstrate reliability, and have the ability to be reprogrammed for different jobs. 57 Performance

54 Calis and Croll, "Robotics and Human Resource Development," 32.

55 Tanner, "Basics of Robotics," 12.

56 Robert Gorman, "Considerations for Selecting Robots," Robotics World (15 August 1984): 18-20.

57 Calis and Croll, "Robotics and Human Resource Development," 32. 
characteristics in the application process consider payload, reach, speed, degree of accuracy, and the repeatability of movements. 58 Robot manufacturers predict that additional capabilities requiring intellectual capacity that are not available at the present time will be available in the near future.59 The programming of a robot is done through the use of a teach pendant, a device that leads the robot through a series of operations which are stored in the robot's memory to repeated later.60

Another factor to be considered in the acquisition of robotics involves the justification required to obtain the capital to purchase robotic technology. The recent fluctuations of the world-wide economy coupled with business. uncertainty have made the decision to invest in robotics a difficult one. It has been suggested that many companies will not introduce robotic technology into their operations because of failure to meet a one or two year payback. ${ }^{61}$ Another aspect impacting the introduction of robotics involves the purchaser's failure to realize that a robot requires a total robotic system in which the robot represents only a portion of the cost. 62

58 Ibid.

59 Ibid., 33.

60 Longmire, "Robots are Joining the Work Force," 55.

61 Lindorff, "Marketing Forecast, The Robot Revolution," 43.

62 Ibid. 


\section{Job Security}

The introduction of robotics on a world-wide basis is inevitable as foreign countries increase competition by automating their manufacturing plants and thus producing goods more efficiently. 63 Consumers will purchase these high quality foreign goods at lower prices, reducing the number of jobs in United States firms. ${ }^{64}$ Therefore, companies must focus on the requirements of competition if there is a potential for beneficial change, otherwise they will suffer. ${ }^{65}$

One study involving the reaction of employees to technological change was conducted by Liker, Roitman, and Roskies. ${ }^{66}$ The team interviewed approximately fifty-three hands-on employees and seven supervisors and managers out of approximately 150 employees. It was found that regardless of the threat of job security, the employees felt that it was necessary for the company to automate in order to survive in the increasingly competitive environment.

63 Byham, "HRD and the Steel-Collar Worker," 62; Don L. Hinmon, "Automation Creates More Jobs Than it Displaces," Manufacturing Systems (Fall
1984): 49.

64 Hinmon, "Automation Creates More Jobs Than it Displaces," 49.

65 S. Russel Craig, "Seeking Strategic Advantage with Technology? Focus on Customer Value!," Long Range Planning (April 1986): 50.

66 Jeffrey K. Liker and Others, "Changing Everything All at Once: Work Life and Technological Change," Sloan Management Review (Summer 1987): 29-47. 
One author states that the concern of an interested society is the displacement of workers and the impact to the labor market, 67 but the real threat faced by American firms is the problem of job loss due to foreign manufacturers utilizing robotics and not job displacement due to robotics. ${ }^{68}$ A study of the Japanese experience with robotics has indicated that the Japanese promoted the robot industry in order to alleviate the effect of projected manpower shortages in the 1970s.69 By studying the projected growth of the robot industry in Japan, the displacement of workers in Japan should start by 1990. It is suggested that the United States should learn from this example and understand the societal impacts before reacting to pressures to meet the Japanese challenge of productivity at all costs. A study of robots in America shows that workers that are already in the work force and those who will be entering the work force in the next decade need mental protection from robots. 70 The protection, according to the study, comes in the form of information and training.

67 Smith, Jr., "Robotics: A Strategic Issue," 9.

68 Hinmon, "Automation Creates More Jobs Than it Displaces," 49; Edward M. Knod, Jr. and Others, "Robotics: Challenge for the Human Resources Manager," 39.

69 Leonard Lynn, "Japanese Robotics: Challenge and-Limited-Exemplar," American Academy Political and Social Sciences Annals (November 1983): 16-

70 John L. Cox and J. Kent Butler, "Human Factors In Robotics: Physical, Mental, Safety, Legal," University of West_Florida and Institute of Technology, Australia (1984): 276. 
In some industries, there is little choice but to automate if companies wish to remain competitive in the world market. ${ }^{71}$ The introduction of new technology in plant modernization programs in the United States is saving jobs that would otherwise be lost to foreign competition. Companies may be forced to adopt a technological strategy which forces changes within the corporate culture in order to survive. 72

The technical aspects of robotics have been addressed in the literature but the effect they have on the human resource element have been largely ignored. ${ }^{73}$ According to a congressional report on human factors, it was noted that there is little emphasis on the human factor in regard to the introduction of technology. 74 Chao and Kozlowski noted that most research on industrial robots conducted to date has been accomplished by engineers and economists who have attempted to examine system performance and forecast occupational and manpower needs while the relationship to

71 Lindorff, "Marketing Forecast, The Robot Revolution," 42; Longmire, "Robots are Joining the Work Force," 54.

72 Henderson, "The Logic of Kanban," 8.

73 Hollon and Rogol, "How Robotization Affects People," 74.

74 "The Human Factor in Innovation and Productivity, Including an Analysis of Hearings on the Human Factor," HSE Committee on Science and Technology 97 Congress 2 Report, by Don Fuqua, Chairman (Washington D.C.: Government Printing Office, October 1982), 1-40. 
organizational behavior has been limited to case studies and anecdotal information. 75

The introduction of technological change and the negative effect it has on the work force is not a new revelation. Trist and Banforth noted the lack of productivity improvement while introducing new methods of coal mining in England. ${ }^{76}$ Robotic technology is currently at the forefront in the ongoing technology debate between man and his machines. ${ }^{77}$ This technology, utilizing the robot, will have a greater impact on the workplace than anything experienced in the past 78 and few organizations left unaffected by its introduction. ${ }^{79}$

The introduction of robotics has been looked upon negatively by workers, supervisors and managers. ${ }^{80}$ Although machines are

75 Georgia T. Chao and Steve W. J. Kozlowski, "Employee Perceptions on the Implementation of Robotic Manufacturing Technology." Journal of Applied Psychology (February 1986): 70-76.

76 E. L. Trist and K. W. Banforth, "Some Social Psychological Consequences of the Longwall Method of Coal-Getting," Human Relations
(1951): 3-38.

77 Knod, Jr. and Others, "Robotics: Challenge for the Human Resources Manager," 38; William R. Loeffler, "Human Factors Engineering and Robotics: Up-dating Quality of Work Life Models," in Robots 9 Conference Proceedings Held in Detroit. Michigan 2-6 June. 1985, (Privately Printed, 1985), 17.

78 Smith, Jr., "Robotics: A Strategic Issue," 7.

79 Ibid., 8.

80 Byham, "HRD and the Steel-Collar Worker," 62; Andrew Kakabadse, "Politics of Planned Change," Industrial Management and Data Systems (September-October 1983): 10. 
actually tools or brain amplifiers, many people perceive robots as replacements for human effort. 81 Workers fear the potential loss of employment, the changes of their job structure, and the reduction opportunities to socialize, 82 while supervisors and managers fear the possible loss of their jobs, perceived increased workloads, loss of status, and the perceived lack of expertise. ${ }^{83}$ Some estimates indicate that flexible manufacturing systems are expected to reduce supervisory labor by twenty-three percent. 84

One study involving the reaction of managers to technological change has been positive. The issue, in the manager's opinion, was not whether new technology should be introduced, but how to ensure that the benefits are maximized. ${ }^{85}$ A study of foremen within four manufacturing and chemical plants also indicated favorable

81 Fred M. Amram, "Robotics: The Human Touch," Robotics Today, Winter 1981-1982, 12; Knod, Jr. and Others, "Robotics: Challenge for the Human
Resources Manager," 40 .

82 Byham, "HRD and the Steel-Collar Worker," 62; Kakabadse, "Politics of Planned Change," 10.

83 Byham, "HRD and the Steel-Collar Worker," 62; Calis and Croll, "Robotics and Human Resource Development," 40; Knod, Jr. and Others, "Robotics: Challenge for the Human Resources Manager," 40; Leap and Pizzolatto, "Robotics Technology: The Implications for Collective Bargaining and Labor Law," 698; Smith, Jr., "Robotics: A Strategic Issue," 9; John Teresko,
"Robots Come of Age," Industry Week (25 January 1982): 38.

84 Anna Kochan, "Putting the U.S. Aerospace Industry on the Right Path," The FMS Magazine, July 1985, 143.

85 Jill E. Davidson, "Tech Change: Boon or Bane for Professionals, Supervisors and Middle Managers," Canadian Public Administrator (Winter 1986): 562-566. 
responses to technology, however, their main concern was job security. ${ }^{86}$ This was explained by the decreasing prestige of foremen due to technological changes within the companies.

While studies show that the root of the workers' fears is the loss of employment, authors do not agree whether job security is or is not a real threat. Present estimates show that robots do the work of anywhere from 1.7 to 6 employees. 87 Since most factories operate on a two-shift basis, the installation of one robot could displace twice that estimated amount.88 It is predicted by some authors that the introduction of robotics will displace many workers and even those who remain will require retraining. ${ }^{89}$ These authors state, however, that many new jobs will be created and these will be more challenging and interesting. 90 A five-year Delphi study of

86 R. C. Schoenfeldt, "The Foreman's Job as Perceived by His Wife," Supervisory Management (September 1980): 9-15.

87 Foulkes and Hirsch, "People Make Robots Work," 94.

88 Calis and Croll, "Robotics and Human Resource Development," 36.

89 Byham, "HRD and the Steel-Collar Worker," 64; Foulkes and Hirsch, "People Make Robots Work," 97; Henderson, "The Logic of Kanban," 12; Levitan and Johnson, "The Future of Work: Does it Belong to Us or to the Robots?", 13.

90 Byham, "HRD and the Steel-Collar Worker," 64; Calis and Croll, "Robotics and Human Resource Development," 36; Foulkes and Hirsch, "People Make Robots Work," 95; Hinmon, "Automation Creates More Jobs Than it Displaces," 48; Knod, Jr. and Others, "Robotics: Challenge for the Human Resources Manager," 41; Longmire, "Robots are Joining the Work Force," 56; Mabry Miller and Thomas $J$. Ault, "The Proactive Face of the Robotics Revolution: Managing the Human Factor," in Robots 9 Conference Proceedings Held in Detroit. Michigan 2-6 June. 1985, (Privately Printed, 1985), 2; Tanner, "What Every Senior Manager Should Know About Robotics," 26; Zemke, "The Robots Are Coming! Training Tomorrow's High Tech Workers," 25. 
robotics trends by the Society of Manufacturing Engineers and the University of Michigan shows robots could displace four percent of the work force throughout industry over the next ten years, but would create nearly fifty thousand related jobs. ${ }^{91}$ Another study of 355 firms and 43 case studies has indicated that future displacement of employees due to technology will affect assembly-type manufacturing, the center of automation, over the next decade. 92

Although indications suggest that the concern over displacement is not immediate, some estimates show that second generation robots with sensor technology, such as rudimentary vision or tactile sense and artificial intelligence, could threaten approximately two million to thirty million jobs before the year 2000.93 Additional evidence indicates that second generation robots could reduce the number of workers in industries such as insurance and banking by thirty percent after 1990.94 19.

91 "Newsbits - Robotics/Automation," Production (November 1985): 17 -

92 Dieter Seitz, "Automation, Employment and Qualification in Future Assembly - Some Results of a Representative Survey," in SME World Congress on the Human Aspects of Automation Held in Montreal. Canada 16-19 September 1984, (Privately Printed, 1984), 641.

93 Byham, "HRD and the Steel-Collar Worker," 60; Foulkes and Hirsch, "People Make Robots Work," 94; Levitan and Johnson, "The Future of Work: Does it Belong to Us or to the Robots?", 12; Tanner, "What Every Senior Manager Should Know About Robotics," 26.

94 Knod, Jr. and Others, "Robotics: Challenge for the Human Resources Manager," 45. 
Some evidence exists that disputes the argument that industrial robots would create massive unemployment, violent reactions by workers, or dramatic changes in manufacturing techniques.95 During the past century, it was predicted that the effects of technology would cause massive unemployment. These predictions proved to be wrong as the working population has increased by a factor of six while employment has increased by a factor of eight.96 It has also been suggested in the literature that the increase in employment in the past was not provided by the traditional sector as it remained fairly stable. It is predicted that information technology will provide opportunities for jobs as it did during the 1970s as seventy-five percent of new jobs, approximately fourteen million of them, were created in this sector.97 Robots have also been portrayed as devices that increase job opportunities. 98 Robots have frequently been introduced as a part of a new facility without threatening existing jobs. In those cases where it was necessary to reduce the number of workers, employment has been

95 Bickerstaffe, "Robotics: Managing the Change in Manufacturing," 20.

96 Hinmon, "Automation Creates More Jobs Than it Displaces," 48; Levitan and Johnson, "The Future of Work: Does it Belong to Us or to the Robots?", 10.

97 Hinmon, "Automation Creates More Jobs Than it Displaces," 49; Knod, Jr. and Others, "Robotics: Challenge for the Human Resources Manager," 41.

98 Ichiro Saga, "Japan's Robots Produce Problems for Workers," The Wall Street Journal, 28 February 1983, 21. 
handled by normal turnover.99 Between seventy and eighty percent of robot installations in 1984 were retrofitted and integrated into existing production lines, but recent evidence suggests that workers are more likely to accept the infusion of technology when it is dedicated to a new product or new process. 100

The evidence suggesting displacement does not seem as bleak when coupled with the predicted shortage of workers by 1995 due to the low birthrate in the 1960s and 1970s and the fact that young adults are staying in school longer.101 Also, the impact of the introduction of robotics may not be as great as predicted due to the lack of support personnel such as trained engineers which could limit the number of robots introduced.102 With annual sales of robots well below ten thousand in a labor force of one hundred million, the impact on unemployment is not anticipated to be great for some

99 Bickerstaffe, "Robotics: Managing the Change in Manufacturing," 20.

100 Foulkes and Hirsch, "People Make Robots Work," 96.

101 Byham, "HRD and the Steel-Collar Worker," 64.

102 Calis and Croll, "Robotics and Human Resource Development," 37; Hinmon, "Automation Creates More Jobs Than it Displaces," 49. 
time, 103 however, it is recognized that in certain industries displacement will increase substantially. 104

As can be seen, there does not appear to be a general consensus on the effect of the introduction of technology, but the fears of massive worker displacement in the near future should be tempered. The immediate factor that companies should address is the reaction of workers to the introduction of robotics. 105 Companies that prepare for the future will realize substantial gains avoiding situations where workers are unemployed.106

In order to gain acceptance and enthusiasm, some companies have considered and instituted rules providing guaranteed employment for those employees affected by the introduction of robotics.107 The advent of the industrial robot has required the redesign of human work activities which help employees accept

103 Foulkes and Hirsch, "People Make Robots Work," 94; Bruce Hoard, "Expert Advises Ways to Ease Robot Installation," Computerworld (15 March 1982): 28; Levitan and Johnson, "The Future of Work: Does it Belong to Us or to
the Robots?", 13 .

104 Bickerstaffe, "Robotics: Managing the Change in Manufacturing," 24; Calis and Croll, "Robotics and Human Resource Development," 37; Hinmon, "Automation Creates More Jobs Than it Displaces," 49.

105 Calis and Croll, "Robotics and Human Resource Development," 37; Knod, Jr. and Others, "Robotics: Challenge for the Human Resources Manager,"
41.

106 Smith, Jr., "Robotics: A Strategic Issue," 9.

107 Byham, "HRD and the Steel-Collar Worker," 62; Foulkes and Hirsch, "People Make Robots Work," 97. 
robots and foster positive attitudes toward job security. 108 Companies have also helped robots gain acceptance in the workplace by showing how robotic technology contributes to raising productivity and maintaining international competitiveness. 109

A study of four central Indiana firms found that subordinates will not adapt to technological change when simply told by their managers why the change is necessary. ${ }^{110}$ The extent to which technological change was accepted by workers was determined by their involvement in planning and implementation of that change. It was found that workers were more receptive to technological changes when they were aware of the benefits for themselves, their customers, and their company. 111

If displacement becomes unavoidable, authors suggest that companies be able to articulate, discuss and defend layoff policies well in advance of the installation.112 A survey indicated that if reeducation and retraining programs are instituted to address the

108 E. Ulich and F. Frei, "Industrial Robots: Threat or Aid to the Humanization of Work?," in Swiss Federal Institute of Technology. IFS Industrial Robots 14th International Symposium / Robot Technical Conference Held in Switzerland 2-4 October 1984, (Privately Printed, 1985), 43-51.

109 Bickerstaffe, "Robotics: Managing the Change in Manufacturing," 21.

110 Timothy A. and Donna M. Matherly, "Employee Participation Eases the Transition to Office Automation," Journal of Systems Management (June 1983): $17-23$.

111 Byham, "HRD and the Steel-Collar Worker," 64.

112 Foulkes and Hirsch, "People Make Robots Work," 97. 
needs of the displaced workers then the effects of unemployment will be lessened.113

Chao and Kozlowski agree that while robots share much in common with existing automated production technologies, robots create unique issues in their integration with human beings. ${ }^{114}$ They emphasize that robots differ from other technological innovations because of widely disseminated popular stereotypes and that reactions toward industrial robots appear to vary across occupational groups. Krasnoff addresses the perception problem that people have toward the robot. ${ }^{115}$ The root of the problem stems from the fact that robots were in the minds of the public before they became a reality and were cast as soulless metal monsters intent on the destruction of mankind. Robots are more threatening to the job security of workers than other forms of automation. These attitudes may have been generated by years of viewing robots in motion pictures. Krasnoff further states that it is the threat of job displacement and the perceptions of the work force that should be examined if the introduction of robots are to succeed.

The advent of new sophisticated robot technology may introduce a different era of conflict between employees and

113 Calis and Croll, "Robotics and Human Resource Development," 37.

114 Chao and Kozlowski, "Employee Perceptions on the Implementation of Robotic Manufacturing Technology." 70-76.

115 Barbara Krasnoff, "Cinema Robots Clash with Reality," Robot/x News (February 1983): 19. 
management.116 One study indicates that the resistance to the introduction of robotics affects every level of worker and management within an organization. ${ }^{117}$ In some companies the employees have given robots names in order to "humanize" them. 118 Some managers believe that this has positive benefits because employees tend to feel more comfortable working with a robot with a name, but other managers believe that this behavior could lead to employee relations problems. 119

The installation of robots in the United States has not gone smoothly, with some cases of sabotage reported. ${ }^{120}$ It has also been noted that resistance to robot introduction may come in the form of apathetic attitudes. ${ }^{121}$ Morale problems can exist even if no workers are actually displaced. 122

Hollon and Rogol examined the attitudes of the chief executive officers of the Fortune 500 firms toward robotics and the executive's perception of the worker's attitude toward robotics. 123 Increasing

116 Foulkes and Hirsch, "People Make Robots Work," 94.

117 Peter T. Stackpole, "Factors Affecting Management's Resistance to Installation of a Robotics System," Technical Paper SME (1983): 911.

118 Foulkes and Hirsch, "People Make Robots Work," 102.

119 Ibid.

120 Byham, "HRD and the Steel-Collar Worker," 60.

121 Calis and Croll, "Robotics and Human Resource Development," 40.

122 Foulkes and Hirsch, "People Make Robots Work," 96.

123 Hollon and Rogol, "How Robotization Affects People," 74-80. 
productivity was found to be the major factor that prompted their introduction. Over eighty-four percent of the CEOs experienced no change in employment while less than eight percent reported a decline. Of importance was the fact that over fifty-eight percent experienced positive reactions by employees, two percent experienced negative reactions, while the remainder of those surveyed experienced worker ambivalence.

Other studies have determined that workers within several industries are concerned with job security due to the introduction of technology. 124 One study that analyzed the introduction of robotics and the effect on job security was conducted by Chao and Kozlowski.125 Questionnaires were administered to three distinct job classes in a manufacturing plant: line workers, job setters, and skilled trades. It was anticipated that employees in different job classes would have different perceptions regarding the planned implementation of industrial robots even though company policy had stated that no jobs would be terminated due to their implementation. Line workers were the most negative about the planned implementation and believed that robots threatened their job

124 Karen A. Krepps, "The Effects of an Experimental Computer Training Program on Effective Job Responses for Employees Converting to an Automated Operation" (Ph.D. diss., Wayne State University, 1986), 1-216; Walter Nordahl Leutz, "Aging and Technological Change: A Case Study of the U.S. Postal Service" (Ph.D. diss., Brandeis University, 1981), 1-315.

125 Chao and Kozlowski, "Employee Perceptions on the Implementation of Robotic Manufacturing Technology," 70-76. 
security while skilled trades regarded robots as non-threatening to their job security and felt generally positive about their implementation. The conclusion of the study stated that employees with greater skills would tend to be more positive about robots and regard the robots as providing opportunities for skill enhancement, while less skilled employees were expected to regard robots as a threat to their security.

A study by Fraser confirmed that employees at different work levels had differences in regard to job security.126 The study found that there were differences in the attitudes of designers, patternmakers, and production managers toward job security with the introduction of computer-aided design.

In a report published by Challis, a dual survey of the opinions of the United States and the United Kingdom on the effect of advanced manufacturing technology had also shown a concern about job security. 127 Nearly one-hundred percent of the United Kingdom respondents over forty-five years of age expressed disquiet with respect to job security. The United States group believed that the production workers and first-line supervisors would have the

126 Annette J. Fraser, "Attitudes of Designers, Patternmakers and Production Managers as Related to Implementation of Computer Aided Design Systems in Apparel Production" (Ph.D. diss., Texas Woman's University, 1984),
$1-184$.

127 Harry Challis, "How Does AMT Affect the Worker," Production Engineer (February 1986): 20-22. 
greatest anxiety while the United Kingdom group saw the greatest anxiety at the senior-management level.

A survey of 323 middle managers within 6 large United Kingdom-based organizations confirm that middle managers are anxious and less likely to make the emotional commitment to their organizations required for introducing new technology.128 They attribute this attitude in part to the lack of job security as the middle managers perceive the rewards for that commitment to be diminishing.

Groves conducted a survey of workers at twenty-two plants and found that forty-five percent of the workers were happy, fortyfive percent didn't care and ten percent were unhappy about working with robots. ${ }^{129}$ The study concluded, however, that in the majority of cases, the unhappiness of workers was due to change and the robot as a symbol of that change and not due to the robot itself.

\section{Labor Unions}

An implication of the effect of robotic technology on the work force involves labor unions. One study that examined the effect of integrating new technology into the work force and its effect on job security focused on the attitude of union leaders toward

128 Robert Goffee and Richard Scase, "Are the Rewards Worth the Effort? Changing Managerial Values in the 1980s," Personnel Review (Winter 1986): 3-6.

129 Brenton R. Groves, "Why Robots Are Feared - Or Are They?," Engineers Australia (19 October 1984): 50-52. 
technological change. ${ }^{130}$ It was found that many of the union leaders expected significant displacement from technological changes. This was suggested not to be a serious problem, however, since there was a rate of displacement found acceptable by the union leaders. It appears that even labor leaders realize that robots contribute to overall job security. ${ }^{131}$ While job security is a main concern, it was determined by labor leaders that technology was seen as a way to improve the competitive state of the industry in the future. The seriousness of the job security problem as viewed by labor leaders arises from the pessimistic attitude about the mobility of workers to other jobs or industries.

The concerns of labor unions focuses primarily on the introduction of robotics to the workplace, procedures relating to worker displacement, and retraining necessitated by the presence of robotics. 132 Union officials are concerned with the potential reduction in size of the bargaining unit and the status of employees who program or maintain robots. 133 It was acknowledged that the

130 Roger Dale Weikle, "The Attitude and Preferences of Local Union Leaders for Adjustment to Technological Change" (Ph.D. diss., University of South Carolina, 1985, 1-273.

131 Bickerstaffe, "Robotics: Managing the Change in Manufacturing," 21; Saga, "Japan's Robots Produce Problems for Workers," 21; Jan Wong and Others, "Robots: Next Step for Garment Makers," The Wall Street Joumal, 7 August 1986, 22.

132 Calis and Croll, "Robotics and Human Resource Development," 37; Foulkes and Hirsch, "People Make Robots Work," 101; Levitan and Johnson, "The Future of Work: Does it Belong to Us or to the Robots?", 12; Longmire, "Robots are Joining the Work Force," 56.

133 Foulkes and Hirsch, "People Make Robots Work," 101. 
maintenance of current wage levels for employees placed into normally lower paying jobs is a frequently utilized collective bargaining tool used to help control the negative aspects of robotics.134 The relative lack of concern by unions over the loss of jobs may indicate that the negative effects of robots on employment have been exaggerated.135

\section{Safety}

An attractive feature of robotics is that they can serve as direct replacements for people who work in hazardous, tedious, or unpleasant jobs. ${ }^{136}$ The emphasis in the United States over the last decade has been on providing cleaner and safer environments for workers, paving the way for worker acceptance of robots in hazardous factory work. ${ }^{137}$ It is in these hostile environments where robots can make positive contributions. ${ }^{138}$

134 Knod, Jr. and Others, "Robotics: Challenge for the Human Resources Manager," 42.

135 Levitan and Johnson, "The Future of Work: Does it Belong to Us or to the Robots?", 13.

136 Bickerstaffe, "Robotics: Managing the Change in Manufacturing," 21; Byham, "HRD and the Steel-Collar Worker," 60; Calis and Croll, "Robotics and Human Resource Development," 31; Foulkes and Hirsch, "People Make Robots Work," 94; Longmire, "Robots are Joining the Work Force," 56.

137 Calis and Croll, "Robotics and Human Resource Development," 34; Knod, Jr. and Others, "Robotics: Challenge for the Human Resources Manager,"

138 Knod, Jr. and Others, "Robotics: Challenge for the Human Resources Manager," 42. 
It should be noted that safety alone may not increase the introduction of robots into the work place. Foulkes and Hirsch cite a study where the desire for profitability jeopardized a robotic project. Although dust and fumes endangered workers, the application was not implemented because it did not show the direct labor savings sought. 139

It is ironic that robots have themselves prompted concerns over worker safety. Safety concerns over the introduction of robots pertain to the safety of the operator or employees working in close proximity to an operating robot. Concerns also arise when workers placed in jobs involving robots turn complacent as they become more familiar with the robot's operations, increasing the likelihood of injury. ${ }^{140}$ While there has been at least one fatality in the United States resulting from working in the robot environment, robots have not proved to be extremely dangerous thus far. ${ }^{141}$ Safety devices, such as microwave and ultrasonic sensors, pressure-sensitive pads and light-beam detection systems are usually installed in order to alleviate any fears of possible injury. ${ }^{142}$

94-102.

140 William M. Bulkekey, "Manufacturers Seek to Create More SafetyConscious Robots," The Wall Street Joumal, 4 October 1985, 23.

141 Ibid.

142 Bulkekey, "Manufacturers Seek to Create More Safety-Conscious Robots," 23; Foulkes and Hirsch, "People Make Robots Work," 101. 


\section{Training}

The first installation of an industrial robot in a company's facility is an important step in the introduction of robotics to the work force. ${ }^{143}$ Some managers have been careful to select a simple first application in the introduction of robotics in order to establish a positive track record and build employee confidence, ${ }^{144}$ This introduction phase in most companies has been gradual and since start-up problems are inevitable, some companies have taken advantage of the debugging process to demonstrate to the employees that a robot is just a machine and, as such, is non-threatening. ${ }^{145}$

The implementation of industrial robots can prove to be disastrous without the proper foresight, thought, and planning. 146 It has been suggested that robotic training should be segregated from other training programs because the area of robotic technology is relatively new and would alleviate worker fears. 147 68.

143 Jarosh, "Prescription for Robotic Success: Right Job, Right Robot,"

144 Foulkes and Hirsch, "People Make Robots Work," 96; Jarosh, "Prescription for Robotic Success: Right Job, Right Robot," 68; Frank R. Skinner and Wesley J. Johnston, "Avoiding Robot Failures," Robotics Today (August 1985): 44.

145 Foulkes and Hirsch, "People Make Robots Work," 101; Nag, "Tricky Technology: Auto Makers Discover 'Factory of the Future' is Headache Just
Now," 1.

146 Geary V. Soska and Carol F. Thompson, "Four-Phase Approach Assures Robot Success," Robotics World (July 1987): 23.

147 Calis and Croll, "Robotics and Human Resource Development," 38. 
Even though the general skills of a robotic system will be applicable to any robot system, a portion of the training should be delayed until the robot vendor is selected. ${ }^{148}$ The robot manufacturer may be the best facilitator of training due to the familiarity of the equipment involved.149 This would give employees the familiarity necessary to operate the particular system purchased. Some managers believe that the training program preceding a robot installation should involve the largest number of employees possible.150 The training for managers must go beyond robotic technology and should also focus on the worker reactions to this technology. 151

There are three basic stages of training proposed by the literature survey.152 Stage one occurs prior to the installation of the robot and is used to give the basic understandings of robotics. 153 The second stage occurs during the robot installation process and

148 Knod, Jr. and Others, "Robotics: Challenge for the Human Resources Manager," 44.

149 Ibid., 42.

150 Foulkes and Hirsch, "People Make Robots Work," 98; Knod, Jr. and Others, "Robotics: Challenge for the Human Resources Manager," 40; Longmire, "Robots are Joining the Work Force," 56.

151 Knod, Jr. and Others, "Robotics: Challenge for the Human Resources Manager," 41.

152 Calis and Croll, "Robotics and Human Resource Development," 38;

Soska and Thompson, "Four-Phase Approach Assures Robot Success," 23.

153 Calis and Croll, "Robotics and Human Resource Development," 38. 
demonstrates the robot and its support system to the company personnel.154 At this point, some training programs add a stage for the engineering design effort associated with the particular application. Stage three is the post installation process and is designed to sharpen those skills not periodically practiced.155 In addition to the three basic stages in the training process, there should be several levels of training available for the various employee levels and various agencies demonstrating economical, technical, and operational features. 156

Robotic training is currently provided by manufacturers, users, and consultants, ${ }^{157}$ however, several universities, junior colleges, and vocational schools are setting up classes and degree programs focusing on robotics. The curriculum is aimed at teaching the technical aspects as well as the effects of the introduction of robotics into a production environment. ${ }^{158}$ It has been suggested that the

\section{Ibid.}

155 Ibid.

156 Calis and Croll, "Robotics and Human Resource Development," 39; Loeffler, "Human Factors Engineering and Robotics: Up-dating Quality of Work Life Models," 20-21.

157 Cathey, "Robots Will Change Managing From Shop Floor to CEO," 39.

158 Byham, "HRD and the Steel-Collar Worker," 62; Paul Cathey, "Robots Will Change Managing From Shop Floor to CEO," Iron_Age (19 November 1982): 39; Longmire, "Robots are Joining the Work Force," 56; Robert E. Newton, "Retraining the Blue-Collar Worker for Robotics," in Robots 9 Conference Proceedings Held in Detroit. Michigan 2-6 June. 1985, (Privately Printed, 1985), 104; "1986 Industry Forecast," Bobotics World (January 1986): 25. 
curriculum for a training and development program should include several levels for different audiences. Some possible courses are the theory of robotics, history of robotics, industrial processes, and current issues arising from the use of robotics. 159

\section{Labor Law}

The introduction of robotics will necessitate the examination of several aspects into the area of labor law and collective bargaining. 160 According to Leap and Pizzolatto, the introduction of robotics may encroach on jobs traditionally held by minorities and women which could be viewed as positive if these employees, as a protected group, are given the opportunity to gain more rewarding and higher paying positions. If job advancement is not possible for these protected groups then the introduction of robotics may lead to litigation involving federal or state fair employment laws. Protected groups may also be undesirably affected if robotics alters the production process schedules or work pace. The introduction of robotics must not single out and adversely affect a specific protected group, otherwise there will be legitimate fair employment problems.

The area of "business necessity" as applied to fair employment practices allows selected discrimination against protected groups if the action can be justified because of excessive costs, differences in

159 Loeffler, "Human Factors Engineering and Robotics: Up-dating Quality of Work Life Models," 23.

160 Leap and Pizzolatto, "Robotics Technology: The Implications for Collective Bargaining and Labor Law," 697. 
efficiency, or safety considerations. The unions have recognized the right of companies to improve work methods and develop more efficient operations even if the permanent number of personnel is reduced, but unions seek to control the rate in which technology is introduced where reductions are deemed necessary.

Costs such as worker compensation insurance may be decreased due to the lack of need for protective shielding, guards, ventilation devices, lighting, and periodic medical examinations. Other potential savings may be available to companies because robots do not require group life or health insurance programs.

Further implications of robotics may involve the Fair Labor Standards Act if employees find that, due to the introduction of robotics, overtime work is no longer required and overtime pay is no longer available in situations where overtime pay has traditionally been relied upon. An additional concern has been voiced by the International Union of Electrical, Radio and Machine Workers (IUE) concerning the possibility that robots might run amok and injure people or may be used as "spies" if outfitted with camera vision devices. 161

\section{Project Management}

It has been suggested that in guiding change within an organization, successful managers should be creative in decision-

161 Bickerstaffe, "Robotics: Managing the Change in Manufacturing," 23. 
making, problem-solving, and communicating information.162 One problem in guiding that change is that management does not receive accurate readings on the success or failure of the introduction of robotic technology.163 The literature suggests that the successful integration of robotic technology is dependent on linking that technology to the company's business strategy, 164 and it may be necessary to install an imaginative and far-sighted strategy to make a smooth transition to whatever direction that robotic technology takes. ${ }^{165}$ This interdependence between robotic technology and business strategy requires that companies make commitments to the integration of advanced manufacturing techniques in terms of research and development. ${ }^{166}$ It should be noted, however, that care should be taken to ensure that both the scope and limitations of a technology-based strategy are realistic. 167

162 Linda S. Ackerman, "Don't Fight Change, Guide It Instead," Office Administration and Automation (July 1984): 26; Foulkes and Hirsch, "People Make Robots Work," 97.

163 Byham, "HRD and the Steel-Collar Worker," 60.

164 John Wyman, "SMS Forum: Technology Myopia - The Need to Think Strategically About Technology," Sloan Management Review (Summer 1985): 63.

24.

165 Bickerstaffe, "Robotics: Managing the Change in Manufacturing,"

166 Vida Scarpello and Others, "Reintegrating $R$ \& D into Business Strategy." The Joumal of Business_Strategy (Spring 1986): 56.

167 Ian Wilson, "The Strategic Management of Technology: Corporate Fad of Strategic Necessity?," Long Range Planning (April 1986): 21. 
One of the biggest obstacles for management concerns the infusion of technology into the existing corporate culture.168 An organization goes through several predictable phases when addressing change and too often executives overlook the human aspect. 169 The management of an organization should consider the compatibility between an organization's technology, its structure and its members and negotiate with the affected departments prior to the introduction of robotics, otherwise negative consequences may ensue. ${ }^{170}$ The most critical period in the operation of a robot is during the introduction period. 171

Project management has gained support in the application of new manufacturing technologies in order to make the organization more efficient and effective in the utilization of corporate resources. 172 Project management was established in order to control specific tasks or discrete projects with identifiable goals and objectives. 173 One of the main advantages of project management in

168 Wyman, "SMS Forum: Technology Myopia - The Need to Think Strategically About Technology," 63.

169 Ackerman, "Don't Fight Change, Guide It Instead," 27; Byham, "HRD and the Steel-Collar Worker," 64.

170 Argote and Others, "The Human Side of Robotics: How Workers React to a Robot," 31; Hoard, "Expert Advises Ways to Ease Robot Installation," 28.

171 Hoard, "Expert Advises Ways to Ease Robot Installation," 28.

172 Harold Kerzner, "Project Management in the Year 2000," Joumal of Systems Management (October 1981): 26: Knod, Jr. and Others, "Robotics: Challenge for the Human Resources Manager," 40.

173 Kerzner, "Project Management in the Year 2000," 26. 
the introduction of robotics is its use of a highly effective multidiscipline approach. 174

Titles, such as "Manager of Robotics" or "Vice President of Robotics", have been predicted to be prominent in organizations in the coming years. ${ }^{175}$ These titles may require individuals to master a variety of disciplines from kinematics to economics, metallurgy to bionics, or systems engineering to digital electronics.176 Even though technical knowledge may be required, it will be necessary for all management levels to have knowledge of human resources and interpersonal relations. 177

174 Ibid., 31.

175 Cathey, "Robots Will Change Managing From Shop Floor to CEO," 37.

176 Ibid.

177 Ibid. 


\section{CHAPTER III}

\section{METHODOLOGY}

\section{Introduction}

This chapter addresses the methodology of the research used in this dissertation. The first area discussed concerns the research design. This area is followed by a discussion of the strength and weakness of the research design in reducing the threats to reliability and validity, definition of terms, the sample, data collection and lastly, data analysis.

\section{Research Design}

This study was based on an employee survey at one aerospace defense company that examined the employee's perceived threat to job security by the introduction of robotics. The initial source of data used in this dissertation was secondary data gathered from a literature survey concerned with the introduction of advanced manufacturing technologies. The literature survey encompassed books and articles, focusing specifically on trade and management journals. The secondary research material was used as a basis for the generation of hypotheses expected to be found in the primary research.

The primary research was obtained from employees within an aerospace defense company through the use of questionnaires. The 
questionnaires were administered to three labor types within the work force. These types were defined as hands-on operators (hourly), support personnel (salary), and management (any supervisory role). The first phase utilized a pretest that sampled the questionnaire prior to the company wide solicitation. The second phase reworded the questionnaire in areas where anomalies or vagueness existed. It was then administered to the three labor types within the work force to employees already involved with robotics and also to those likely to be involved with robotics in the future. Phase three consisted of data reduction and the comparison of the primary data to the research hypotheses.

\section{Reliability and Validity}

Reliability is a measurement that indicates the extent to which an experiment, test, or measuring procedure yields the same results on repeated trials. The questionnaire instrument did not use common scales in order to obtain data nor were there repeated surveys or redundant questions. The questionnaire instrument used in this study was created to gather information on a variety of subjects, therefore reliability was assumed.

Validity is the degree to which the instrument being used is measuring what it was intended to measure. Expert validity is one approach in ensuring that measurements are valid. Experts are given the instrument to determine whether or not the instrument is measuring what it was intended to measure. The instrument used in 
this study was given to five individuals of the aerospace defense company that specializes in the introduction of robotic technology into the work force. In addition to soliciting expert opinion, the instrument was pretested in order to eliminate any anomalies or vagueness that existed. There were no anomalies found in the pretest and the robotic experts found the measurements of the questionnaire valid.

In order to eliminate any bias that the researcher may have, the instrument was prepared utilizing the main topics included within the literature. This was accomplished in order to remove any question as to the content validity. Also, to eliminate researcher bias, sealed envelopes were utilized to give assurances to the participants that their responses would remain anonymous.

\section{Definition of Terms}

To facilitate this research, the following definition of terms were used:

Chi square statistic - the statistic that tests for independence between two or more variables by cross-classifications. ${ }^{1}$

1 Henry T. Reynolds, The Analysis of Cross-Classifications (New York: The Free Press, 1977), 7. 
Frequency distribution - the statistical method that indicates the number of responses for each answer to a given question. ${ }^{2}$

Gamma - the statistical method that determines the probability that a random pair of observations is concordant minus the probability that the pair is discordant, assuming the absence of ties. ${ }^{3}$

Independence - the probability of one event not being affected by the occurrence or non-occurrence of another event. ${ }^{4}$

Proportional reduction in error (PRE) - a test that measures associations based on the prediction of the outcome of one variable on another variable. 5

Robot - a reprogrammable multi-functional manipulator designed to move materials, parts, tools, and specialized devices through

2 Marija J. Norusis, SPSS/PC+ The Statistical Package for the Social Sciences - Base Manual - V2.0 (Chicago, IL: Privately Printed,1988) 71-75.

3 Ibid., 103.

4 Reynolds, 7.

5 Ibid., 47. 
variable programmed motions for the performance of a variety of tasks. ${ }^{6}$

\section{The Sample}

The aerospace defense company that was the focus of the survey had robots in place and planned to install several additional robots over the next few years. The employees that were the population of this examination were located on the first shift within the production department of the company. A simple random sampling was utilized for each of the three work groups by selecting one individual every three minutes starting thirty-three minutes before the start of the first shift at each of the 12 entrance gates over a 12 day period. One gate was selected for each day. The times of selection were $6: 27,6: 30,6: 33,6: 36,6: 39,6: 42,6: 45,6: 48,6: 51$, and $6: 54$ in the morning. A simple random sample selects items in such a way that each individual in the population (approximately 9,650 manufacturing workers) had an equal probability of being selected. 7 This allows the advantage of removing any research bias which might result from the exercise of personnel judgement in the selection process.

6 Charles J. Hollon and George N. Rogol, "How Robotization Affects People," Business Horizons (May-June 1985):, 76; Colin Norman, "The New Industrial Revolution," Futurist (February 1981): 35.

7 Charles T. Clark and Lawrence L. Schkade, Statistical Analysis for Administrative Decisions, 2d ed. (Cincinnati OH: Southwestem Publishing
Company, 1974) 232 . 
Based on an estimated completion rate of sixty-five percent, a sample size of a minimum of one hundred twenty questionnaires were solicited in order to yield a minimum seventy-eight usable instruments. Surveys containing at least seventy-five responses are satisfactory for most cases that use the chi square statistic. ${ }^{8}$

The number of questionnaires that were solicited varied for each of the three labor types. Of the 120 solicited instruments, it was expected that the distribution would approximate eighty-six instruments or seventy-two percent for the hands-on operator, sixteen instruments or thirteen percent for support personnel and eighteen instruments or fifteen percent for management.

\section{Data Collection}

The questionnaires were administered to the employees at the entrance gates of the aerospace defense company before the first work shift. This approach yielded a higher response rate than would have normally been achieved through direct mail participation.

A copy of the participant request letter and the questionnaire instrument are included in Appendices A and B. The instrument was developed utilizing concepts derived from the literature survey. As can be noted from the instrument, the information collected was nominal data, therefore the chi square test was selected as the appropriate test of hypotheses. 9

8 Reynolds, 5.

9 Ibid, 16. 


\section{Data Analysis}

Frequency distributions and chi square statistical techniques provided by the Statistical Package for the Social Sciences (SPSS/PC+) available at the University of North Texas were used to analyze the questionnaire data.10 Frequency distributions are one statistical method that indicates the total number of responses to each possible answer for each question while the chi square test statistic is based on the difference between the observed and expected frequencies.

The proportional reduction in error (PRE) measurement was also used in order to avoid any weakness of indices based on the chi square statistic.11 Gamma determines the probability that a random pair of observations is concordant minus the probability that the pair is discordant and was selected as the PRE measurement used in this dissertation. The survey key used to input the questionnaire data into the SPSS/PC+ model is shown in Appendix C.

10 Norusis, 97-99.

11 Reynolds, 47. 


\section{CHAPTER IV}

\section{RESEARCH FINDINGS}

\section{Introduction}

This chapter discusses the research findings for this dissertation and is divided into two areas, frequency distributions and cross-tabulations. The survey yielded 89 usable instruments out of the 120 solicited for a completion rate of more than 74 percent. This completition rate was greater than the required rate necessary for chi square cross-tabulations. The responses were as follows; sixty-six questionnaires, seventy-four percent, for the hands-on operator; fourteen questionnaires, sixteen percent, for support personnel; and nine questionnaires, ten percent for management.

\section{Frequency Distributions}

Frequency distributions were the first statistical method used in the examination of the questionnaire results. Frequency distributions were employed to indicate the number of responses for each answer to a given question. ${ }^{1}$ Percentages were determined by taking the ratio of total responses of one answer to the total number of responses to a given question.

1 Marija J. Norusis, SPSS/PC+ The Statistical Package for the Social Sciences - Base Manual - V2.0 (Chicago, IL: Privately Printed, 1988), 71-75. 
There were twenty-six questions in the survey instrument.

Part I consisting of the first six questions examined the demographic characteristics of those individuals sampled. The percentage of male respondents to female respondents were four times as great, 80.9 percent to 19.1 percent respectively (See Table 1).

TABLE 1

WORKER GENDER

\begin{tabular}{c|c|c}
\hline Response & Frequency & Percent \\
\hline Male & 72 & 80.9 \\
Female & 17 & 19.1 \\
\hline Total & 89 & 100.0 \\
\hline
\end{tabular}

Further demographies included age dispersion, years employed by the company, years at the present position, labor type and education level (See Tables 2 through 6). It should be noted that all percentages in the tables are rounded to the nearest one-tenth percent.

TABLE 2

WORKER AGE

\begin{tabular}{c|c|c}
\hline Response & Frequency & Percent \\
\hline 20 Years and Under & 4 & 4.5 \\
21 Years to 30 Years & 26 & 29.2 \\
31 Years to 40 Years & 32 & 36.0 \\
41 Years to 50 Years & 16 & 18.0 \\
51 Years and Older & 11 & 12.4 \\
\hline Total & 89 & 100.0 \\
\hline
\end{tabular}


TABLE 3

YEARS THAT WORKER HAS BEEN EMPLOYED WITH THE COMPANY

\begin{tabular}{c|c|c}
\hline \hline Response & Frequency & Percent \\
\hline 5 Years or Less & 19 & 21.3 \\
6 Years to 10 Years & 30 & 33.7 \\
11 Years to 15 Years & 10 & 11.2 \\
16 Years to 20 Years & 10 & 11.2 \\
21 Years to 25 Years & 14 & 15.7 \\
26 Years or More & 6 & 6.7 \\
\hline Total & 89 & 100.0 \\
\hline
\end{tabular}

TABLE 4

YEARS THAT WORKER HAS BEEN AT PRESENT POSITION WITHIN THE COMPANY

\begin{tabular}{c|c|c}
\hline \hline Response & Frequency & Percent \\
\hline 1 Year or Less & 14 & 15.7 \\
2 Years to 3 Years & 34 & 38.2 \\
4 Years to 5 Years & 23 & 25.8 \\
6 Years to 7 Years & 11 & 12.4 \\
8 Years to 9 Years & 4 & 4.5 \\
10 Years or More & 3 & 3.4 \\
\hline Total & 89 & 100.0 \\
\hline
\end{tabular}

TABLE 5

CURRENT LABOR TYPE OF THE WORKER WITHIN THE COMPANY

\begin{tabular}{c|c|c}
\hline \hline Response & Frequency & Percent \\
\hline Union & 66 & 74.2 \\
Professional & 14 & 15.7 \\
Management & 9 & 10.1 \\
\hline Total & 89 & 100.0 \\
\hline
\end{tabular}


TABLE 6

\section{EDUCATION LEVEL OF WORKER}

\begin{tabular}{c|c|c}
\hline Response & Frequency & Percent \\
\hline No High School & 1 & 1.1 \\
Some High School & 5 & 5.6 \\
High School Degree & 44 & 49.4 \\
Some College & 18 & 20.2 \\
College Degree & 20 & 22.5 \\
Some Post graduate & 0 & 0.0 \\
post Graduate Degree & 1 & 1.1 \\
\hline Total & 89 & 100.0 \\
\hline
\end{tabular}

Question number 7, regarding the use of robots, was an insurance check to assure that those responding had awareness of the introduction and operation of robots within their company. As shown in Table 7, all respondents were aware of the use of robots in their company.

TABLE 7

COMPANY USES ROBOTS

\begin{tabular}{c|c|c}
\hline \hline Response & Frequency & Percent \\
\hline Uses & 89 & 100.0 \\
Does Not Use & 0 & 0.0 \\
Plans To Use & 0 & 0.0 \\
\hline Total & 89 & 100.0 \\
\hline
\end{tabular}

The second section of the questionnaire examined the impact of robotics to job security. As shown in Table 8 , there was a perception that the introduction of robots threaten 78.7 percent of workers to some degree. When asked what the respondents believed their co- 
workers felt toward the introduction of robotics, this percentage increased to 86.5 percent (See Table 9).

TABLE 8

THREAT TO WORKER JOB SECURITY

\begin{tabular}{c|c|c}
\hline \hline Response & Frequency & Percent \\
\hline High & 30 & 33.7 \\
Medium & 22 & 24.7 \\
Low & 18 & 20.2 \\
None & 19 & 21.3 \\
\hline Total & 89 & 100.0 \\
\hline
\end{tabular}

TABLE 9

THREAT TO CO-WORKER'S JOB SECURITY

\begin{tabular}{c|c|c}
\hline Response & Frequency & Percent \\
\hline High & 49 & 55.1 \\
Medium & 15 & 16.9 \\
Low & 13 & 14.6 \\
None & 12 & 13.5 \\
\hline Total & 89 & 100.0 \\
\hline
\end{tabular}

Workers were asked what they felt was the major factor that prompted the introduction of robots within their company. As shown in Table 10, lowering labor costs was the overwhelming response with 61.8 percent. Increasing production came in second with 33.7 percent followed by expanding production, 3.4 percent, with one respondent indicating that the introduction of robots was a "marketing tool". 
TABLE 10

BELIEF OF WORKER AS TO THE MAJOR FACTOR FOR ROBOT INTRODUCTION

\begin{tabular}{c|c|c}
\hline \hline Response & Frequency & Percent \\
\hline Increase Productivity & 30 & 33.7 \\
Improve Quality & 0 & 0.0 \\
Reducing Hazards & 0 & 0.0 \\
Lower Labor Costs & 55 & 61.8 \\
Expand Production & 3 & 3.4 \\
Other & 1 & 1.1 \\
No Opinion & 0 & 0.0 \\
\hline Total & 89 & 100.0 \\
\hline
\end{tabular}

The respondents were asked what they believed their coworkers felt was the major factor for the introduction of robots. Over seventy percent of those surveyed believed that their coworkers would state that lowering labor costs was the major factor with 23.6 percent stating their co-workers would indicate that the introduction of robots was due to increasing productivity (See Table 11). One individual stated that co-workers believed the major factor was "greed".

Question 12 asked the workers to respond to the impact that the introduction of robotics had on the employment level in their company. As shown in Table 12, 53.9 percent indicated there was no change to employment while 43.8 percent stated that employment decreased. Only two respondents indicated that employment increased.

The survey asked workers to respond to what they believed their co-workers felt toward the effect that the introduction of robots 
TABLE 11

BELIEF OF CO-WORKER AS TO THE MAJOR FACTOR FOR ROBOT INTRODUCTION

\begin{tabular}{c|c|c}
\hline \hline Response & Frequency & Percent \\
\hline Increase Productivity & 21 & 23.6 \\
Improve Quality & 2 & 2.2 \\
Reducing Hazards & 0 & 0.0 \\
Lower Labor Costs & 63 & 70.8 \\
Expand Production & 2 & 2.2 \\
Other & 1 & 1.1 \\
No Opinion & 0 & 0.0 \\
\hline Total & 89 & 100.0 \\
\hline
\end{tabular}

TABLE 12

OPINION OF WORKER ON THE EFFECT OF ROBOTS TO THE EMPLOYMENT LEVEL OF THE COMPANY

\begin{tabular}{c|c|c}
\hline \hline Response & Frequency & Percent \\
\hline Decreased & 39 & 43.8 \\
No Change & 48 & 53.9 \\
Increased & 2 & 2.2 \\
No Opinion & 0 & 0.0 \\
\hline Total & 89 & 100.0 \\
\hline
\end{tabular}

had on the employee level at their company. The results indicated that the respondents felt that a larger percentage of their co-workers believed that the introduction of robotics decreased the employment level in their company. As shown in Table 13, the response showing decreased employment rose to 68.5 percent while 31.5 percent indicated no change.

Question number 15 asked those workers surveyed to respond to a statement that chronic unemployment among displaced workers 
TABLE 13

OPINION OF CO-WORKER ON THE EFFECT OF ROBOTS TO THE EMPLOYMENT LEVEL OF THE COMPANY

\begin{tabular}{c|c|c}
\hline \hline Response & Frequency & Percent \\
\hline Decreased & 61 & 68.5 \\
No Change & 28 & 31.5 \\
Increased & 0 & 0.0 \\
No Opinion & 0 & 0.0 \\
\hline Total & 89 & 100.0 \\
\hline
\end{tabular}

would result from the increased usage of robots. As shown in Table $14,60.7$ percent of the respondents agreed with this statement, 38.2 percent disagreed and one individual had no opinion.

TABLE 14

RESPONSE OF WORKER TO STATEMENT REGARDING CHRONIC UNEMPLOYMENT AMONG DISPLACED WORKERS RESULTING FROM THE INCREASED USAGE OF ROBOTS

\begin{tabular}{c|c|c}
\hline \hline Response & Frequency & Percent \\
\hline Agree & 54 & 60.7 \\
Disagree & 34 & 38.2 \\
No Opinion & 1 & 1.1 \\
\hline Total & 89 & 100.0 \\
\hline
\end{tabular}

Those surveyed were asked to respond if they believed their co-workers agreed with their opinion on the previous question regarding chronic unemployment due to the increased usage of robots. Table 15 indicates that 86.5 percent of those surveyed believed that their co-workers would agree while 12.4 percent would disagree. 
TABLE 15

CO-WORKERS AGREE WITH RESPONDENT TO STATEMENT REGARDING CHRONIC UNEMPLOYMENT AMONG DISPLACED WORKERS RESULTING FROM THE INCREASED USAGE OF ROBOTS

\begin{tabular}{c|c|c}
\hline Response & Frequency & Percent \\
\hline Yes & 77 & 86.5 \\
No & 11 & 12.4 \\
No Opinion & 1 & 1.1 \\
\hline Total & 89 & 100.0 \\
\hline
\end{tabular}

A majority of 56.2 percent of the respondents stated that when employees were confronted with the introduction of robots, the reaction of workers was negative and 14.6 percent stated the reaction was strongly negative. Less than four percent of those surveyed stated that the response to the introduction of robots was positive (See Table 16).

TABLE 16

REACTION OF WORKER WHEN CONFRONTED WITH THE INTRODUCTION OFROBOTS

\begin{tabular}{c|c|c}
\hline Response & Frequency & Percent \\
\hline Strongly Positive & 0 & 0.0 \\
Positive & 3 & 3.4 \\
Neutral & 21 & 23.6 \\
Negative & 50 & 56.2 \\
Strongly Negative & 13 & 14.6 \\
No Opinion & 2 & 2.2 \\
\hline Total & 89 & 100.0 \\
\hline
\end{tabular}


The questionnaire asked the workers to indicate what was done to reduce worker apprehension to facilitate the introduction of robots into the workplace. The majority, 61.8 percent, stated that nothing was done while 18 percent indicated that discussion techniques were utilized. The remaining responses were split among notification to union, 7.9 percent, participation, 6.7 percent, skill training, 3.4 percent, and 2.2 percent had no opinion (See Table 17).

\section{TABLE 17}

WHAT WAS DONE TO REDUCE WORKER APPREHENSION TO FACILITATE THE INTRODUCTION OF ROBOTS

\begin{tabular}{c|c|c}
\hline \hline Response & Frequency & Percent \\
\hline Discussion & 16 & 18.0 \\
Skill Training & 3 & 3.4 \\
Participation & 6 & 6.7 \\
Notification To Union & 7 & 7.9 \\
None & 55 & 61.8 \\
Other & 0 & 0.0 \\
No Opinion & 2 & 2.2 \\
\hline Total & 89 & 100.0 \\
\hline
\end{tabular}

The third section of the questionnaire instrument addressed the area of training in the introduction of robots. Question number 18 asked the respondents to give their opinion on whether or not their company had a policy of retraining displaced workers. As shown on Table 18, 28.1 percent believed that a policy did exist while 71.9 percent believed it did not. Those individuals that stated the company had a retraining policy were asked if they believed the policy had been implemented. Twenty-two of the 25 respondents 
stated that they believed the retraining policy had been implemented (See Table 19).

TABLE 18

OPINION OF WORKER ON WHETHER OR NOT THE COMPANY HAS A POLICY OF RETRAINING DISPLACED WORKERS

\begin{tabular}{c|c|c}
\hline \hline Response & Frequency & Percent \\
\hline Yes & 25 & 28.1 \\
No & 64 & 71.9 \\
No Opinion & 0 & 0.0 \\
\hline Total & 89 & 100.0 \\
\hline
\end{tabular}

TABLE 19

OPINION OF WORKER ON WHETHER OR NOT THE POLICY WAS IMPLEMENTED (IF ANSWER TO PREVIOUS QUESTION WAS YES)

\begin{tabular}{c|c|c}
\hline \hline Response & Frequency & Percent \\
\hline Yes & 22 & 88.0 \\
No & 1 & 4.0 \\
No Opinion & 2 & 8.0 \\
\hline Total & 25 & 100.0 \\
\hline
\end{tabular}

The questionnaire asked the respondents if they believed their co-workers felt there was a retraining policy and, if so, if they believed their co-workers felt it was implemented. The respondents indicated that they believed that fewer of their co-workers felt that a policy existed or was implemented (See Tables 20 and 21).

The survey asked the respondents to indicate what degree of responsibility did they believe the individual, company, education, government and unions should have in retraining employees 
TABLE 20

OPINION OF CO-WORKER ON WHETHER OR NOT THE COMPANY HAS A POLICY OF RETRAINING DISPLACED WORKERS

\begin{tabular}{c|c|c}
\hline \hline Response & Frequency & Percent \\
\hline Yes & 18 & 20.2 \\
No & 70 & 78.7 \\
No Opinion & 1 & 1.1 \\
\hline Total & 89 & 100.0 \\
\hline
\end{tabular}

TABLE 21

OPINION OF CO-WORKER ON WHETHER OR NOT THE POLICY WAS IMPLEMENTED (IF ANSWER TO PREVIOUS QUESTION WAS YES)

\begin{tabular}{c|c|c}
\hline Response & Frequency & Percent \\
\hline Yes & 17 & 94.0 \\
No & 0 & 0.0 \\
No Opinion & 1 & 6.0 \\
\hline Total & 18 & 100.0 \\
\hline
\end{tabular}

displaced by robots. The responses ranged from a maximum degree of responsibility for a company with a mean of 2.562 to a minimum for the government with a mean of 1.236 (See Tables 22 through 26).

TABLE 22

DEGREE OF RESPONSIBILITY THE INDIVIDUAL SHOULD HAVE IN RETRAINING DUE TO DISPLACEMENT BY ROBOTS

\begin{tabular}{c|c|c}
\hline \hline Response & Frequency & Percent \\
\hline Minimum & 28 & 31.5 \\
Moderate & 30 & 33.7 \\
Maximum & 31 & 34.8 \\
\hline Total & 89 & 100.0 \\
\hline
\end{tabular}

Note: Mean $=2.034$, Standard Deviation $=.818$ 
TABLE 23

DEGREE OF RESPONSIBILITY THE COMPANY SHOULD HAVE IN RETRAINING EMPLOYEES DISPLACED BY ROBOTS

\begin{tabular}{c|c|c}
\hline \hline Response & Frequency & Percent \\
\hline Minimum & 8 & 9.0 \\
Moderate & 23 & 25.8 \\
Maximum & 58 & 65.2 \\
\hline Total & 89 & 100.0 \\
\hline
\end{tabular}

Note: Mean $=2.562$, Standard Deviation $=.656$

TABLE 24

DEGREE OF RESPONSIBILITY THAT EDUCATION SHOULD HAVE IN RETRAINING EMPLOYEES DISPLACED BY ROBOTS

\begin{tabular}{c|c|c}
\hline \hline Response & Frequency & Percent \\
\hline Minimum & 17 & 19.3 \\
Moderate & 59 & 67.0 \\
Maximum & 12 & 13.6 \\
\hline Total & 88 & 100.0 \\
\hline
\end{tabular}

Note: Mean $=1.921$, Standard Deviation $=.607$

TABLE 25

DEGREE OF RESPONSIBILITY THAT GOVERNMENT SHOULD HAVE IN RETRAINING EMPLOYEES DISPLACED BY ROBOTS

\begin{tabular}{c|c|c}
\hline \hline Response & Frequency & Percent \\
\hline Minimum & 69 & 77.5 \\
Moderate & 19 & 21.3 \\
Maximum & 1 & 1.1 \\
\hline Total & 89 & 100.0 \\
\hline
\end{tabular}

Note: Mean $=1.236$, Standard Deviation $=.453$ 
TABLE 26

DEGREE OF RESPONSIBILITY THAT UNIONS SHOULD HAVE IN RETRAINING EMPLOYEES DISPLACED BY ROBOTS

\begin{tabular}{c|c|c}
\hline \hline Response & Frequency & Percent \\
\hline Minimum & 36 & 40.4 \\
Moderate & 36 & 40.4 \\
Maximum & 17 & 19.1 \\
\hline Total & 89 & 100.0 \\
\hline
\end{tabular}

Note: Mean $=1.787$, Standard Deviation $=.746$

The last section of the questionnaire examined the effect of robots on competition and safety. Question 23 asked the respondents whether robots can reduce the safety and health hazards of a company. As shown on Table 27,83.1 percent believed that robots could reduce these hazards. Conversely, 29.2 percent stated that robots reduced or would reduce the safety and health hazards of their company (See Table 28).

TABLE 27

BELIEF OF WORKER ON WHETHER ROBOTS CAN REDUCE THE SAFETY AND HEALTH HAZARDS OF A COMPANY

\begin{tabular}{c|c|c}
\hline \hline Response & Frequency & Percent \\
\hline Yes & 74 & 83.1 \\
No & 15 & 16.9 \\
No Opinion & 0 & 0.0 \\
\hline Total & 89 & 100.0 \\
\hline
\end{tabular}

The survey asked the respondents to indicate if robots could make a company more competitive. Over 58 percent stated that 
TABLE 28

BELIEF OF WORKER ON WHETHER ROBOTS CAN REDUCE THE SAFETY AND HEALTH HAZARDS OF THEIR COMPANY

\begin{tabular}{c|c|c}
\hline \hline Response & Frequency & Percent \\
\hline Yes & 26 & 29.2 \\
No & 63 & 70.8 \\
No Opinion & 0 & 0.0 \\
\hline Total & 89 & 100.0 \\
\hline
\end{tabular}

robots can make a company more competitive (See Table 29). However, only 21.3 percent of those surveyed stated that robots have made or would make their company more competitive (See Table 30).

TABLE 29

BELIEF OF WORKER ON WHETHER ROBOTS CAN MAKE A COMPANY MORE COMPETITIVE

\begin{tabular}{c|c|c}
\hline \hline Response & Frequency & Percent \\
\hline Yes & 52 & 58.4 \\
No & 36 & 40.4 \\
No Opinion & 1 & 1.1 \\
\hline Total & 89 & 100.0 \\
\hline
\end{tabular}

TABLE 30

BELIEF OF WORKER ON WHETHER ROBOTS CAN MAKE THEIR COMPANY MORE COMPETITIVE

\begin{tabular}{c|c|c}
\hline \hline Response & Frequency & Percent \\
\hline Yes & 19 & 21.3 \\
No & 69 & 77.5 \\
No Opinion & 1 & 1.1 \\
\hline Total & 89 & 100.0 \\
\hline
\end{tabular}




\section{Cross-Tabulations}

The second statistical method used in the examination of the questionnaire results was the use of cross-tabulations using the chi square test. The chi square statistic tests for independence between the row and column variables in an I by $\mathrm{J}$ cross-classification. ${ }^{2}$ The hypotheses postulated in this dissertation assume that the tested variable of a cross-tabulation are independent of each other. Two variables are independent if the possibility that a case falls into a cell is the product of the marginal probabilities of the two categories defining the cell. ${ }^{3}$ This analysis cross-tabulated question 5 to questions 8 through 26 . The dependent variables used in this analysis were hands-on employees, support personnel and management workers found in question 5 with the remaining questions having the independent variables. The following tables will display the data with the observed frequency at the top, the expected frequency in the middle and the marginals at the bottom of each cell. The cross-tabulation of question 5, labor type, to question 8 , threat to job security, is shown in Table 31.

The probability that a hands-on employee perceives a high threat to job security is the product of the probability of being a hands-on employee and having a perception of a high threat. Over 74 percent of the responses were from hands-on employees and the

2 Henry T. Reynolds, The Analysis of Cross-Classifications (New York: The Free Press, 1977), 7.

3 Norusis, 97. 
TABLE 31

CROSS-TABULATION OF QUESTION 5 TO QUESTION 8 - LABOR TYPE TO JOB SECURITY THREAT

\begin{tabular}{c|c|c|c|c|c}
\hline \hline Variables & High & Med & Low & None & Total \\
\hline \multirow{3}{*}{ Union } & 29 & 21 & 11 & 5 & 66 \\
& 22.2 & 16.3 & 13.3 & 14.1 & \\
& 6.8 & 4.7 & -2.3 & -9.1 & \\
\hline \multirow{3}{*}{ Prof } & 1 & 1 & 4 & 8 & 14 \\
& 4.7 & 3.5 & 2.8 & 3.0 & \\
& -3.7 & -2.5 & 1.2 & 5.0 & \\
Mgt & 0 & 0 & 3 & 6 & 9 \\
& 3.0 & 2.2 & 1.8 & 1.9 & \\
\hline total & -3.0 & -2.2 & 1.2 & 4.1 & \\
\hline
\end{tabular}

Note: Chi Square $=37.91913$, Degrees of Freedom $=6$, Significance Level $=.0000$, Gamma $=.83850$

over 33 percent of the responses indicated a perception of having a high threat. Therefore, the probability of being a hands-on employee and perceiving a high threat to job security is established to be .250 .

As shown in Table 31, the null hypothesis stating the two variables are independent was rejected and the research hypothesis was accepted because the significance level for a chi square of 37.91913 with 6 degrees of freedom is .0000 . If being a hands-on employee and perceiving a high threat to job security are independent, the probability that a random sample would result in a chi square of at least that magnitude is less than .05 . The significance level of .05 was the criteria for significance in this dissertation. It should be noted that the SPSS/PC+ statistical package 
rounds the level of significance to four decimal places. Any value of significance less than .0001 is shown as 0.0000 .

Proportional reductions of errors (PRE) are alternatives to chi square-based measurements. These measures are ratios of a measure of error in predicting the value of one variable based on that variable alone and the same measure of error applied to predictors based on knowledge of an additional variable. 4

Gamma, the PRE measure for this dissertation, is the statistical method that determines the probability that a random pair of observations is concordant minus the probability that the pair is discordant, assuming the absence of ties. ${ }^{5}$ A pair of cases are concordant if the values of variables for one case is higher or lower than the corresponding values for the other case. A pair is discordant if the value of one variable is larger than the corresponding value for the other case and the direction is reversed for the second variable.

Gamma ranges from 0 for independence to 1 for dependence. The value of gamma for table 31 is .83850 , showing there is evidence for dependence. Therefore, both chi square and gamma support a position that the introduction of robots is seen as a higher threat to the job security by hands-on employees than by support personnel or managers.
4 Ibid., 100.
5 Ibid., 103. 
The results of the cross-tabulation of labor type to the perception of respondents that the threat of their co-workers to the introduction of robotics is shown in Table 32. A chi square of 74.02920 with 6 degrees of freedom gives a significance level of .0000 indicating that the hands-on employees perceive that their coworkers also perceive a higher threat to job security than support personnel or managers. The .92313 value of gamma gives additional evidence for dependence between the two variables.

\section{TABLE 32}

CROSS-TABULATION OF QUESTION 5 TO QUESTION 9 - LABOR TYPE TO JOB SECURITY THREAT FOR CO-WORKERS

\begin{tabular}{c|c|c|c|c|c}
\hline \hline Variables & High & Med & Low & None & Total \\
\hline \multirow{3}{*}{ Union } & 48 & 15 & 3 & 0 & 66 \\
& 36.3 & 11.1 & 9.6 & 8.9 & \\
& 11.7 & 3.9 & -6.6 & -8.9 & \\
\hline \multirow{3}{*}{ Prof } & 1 & 0 & 5 & 8 & 14 \\
& 7.7 & 2.4 & 2.0 & 1.9 & \\
& -6.7 & -2.4 & 3.0 & 6.1 & \\
\hline \multirow{3}{*}{ Mgt } & 0 & 0 & 5 & 4 & 9 \\
& 5.0 & 1.5 & 1.3 & 1.2 & \\
\hline Total & -5.0 & -1.5 & 3.7 & 2.8 & \\
\hline
\end{tabular}

Note: Chi Square $=74.02920$, Degrees of Freedom $=6$, Significance Level $=.0000$, Gamma $=.92313$

Table 33 shows the results of a cross-tabulation between labor type and the main factor selected in the introduction of robots. The chi square has a computed value of 52.53623 with 6 degrees of freedom giving a significance level of .0000 . The results indicate that 
the hands-on employees believe that the lowering of labor costs was the prime reason for the introduction of robots while support personnel and management workers believe that the introduction was due to increasing productivity. The value of gamma was .53359 , indicating a neutral position for dependence between the variables.

TABLE 33

CROSS-TABULATION OF QUESTION 5 TO QUESTION 10 - LABOR TYPE TO MAIN INTRODUCTION FACTOR

\begin{tabular}{|c|c|c|c|c|c|}
\hline Variables & $\begin{array}{l}\text { Produc- } \\
\text { tivity }\end{array}$ & $\begin{array}{c}\text { Labor } \\
\text { Costs }\end{array}$ & $\begin{array}{c}\text { Expand } \\
\text { Prod }\end{array}$ & Other & Total \\
\hline Union & $\begin{array}{c}12 \\
22.2 \\
-10.2 \\
\end{array}$ & $\begin{array}{c}54 \\
40.8 \\
13.2 \\
\end{array}$ & $\begin{array}{c}0 \\
2.2 \\
-2.2 \\
\end{array}$ & $\begin{array}{c}0 \\
.7 \\
-.7\end{array}$ & 66 \\
\hline Prof & $\begin{array}{l}11 \\
4.7 \\
6.3 \\
\end{array}$ & $\begin{array}{c}1 \\
8.7 \\
-7.7 \\
\end{array}$ & $\begin{array}{c}2 \\
.5 \\
1.5 \\
\end{array}$ & $\begin{array}{c}0 \\
.2 \\
-.2\end{array}$ & 14 \\
\hline $\mathrm{Mgt}$ & $\begin{array}{c}7 \\
3.0 \\
4.0\end{array}$ & $\begin{array}{c}0 \\
5.6 \\
-5.6 \\
\end{array}$ & $\begin{array}{l}1 \\
.3 \\
.7 \\
\end{array}$ & $\begin{array}{l}1 \\
.1 \\
.9\end{array}$ & 9 \\
\hline Total & 30 & 55 & 3 & 1 & 89 \\
\hline
\end{tabular}

Note: Chi Square $=52.53623$, Degrees of Freedom $=6$, Significance Level $=.0000$, Gamma $=-.53359$

The respondents indicated that the hands-on employees believed that their co-workers also believed lowering labor costs was the main factor in the introduction of robotics while support personnel and management workers believe that it was due to increasing productivity (See Table 34 ). The results of the cross- 
tabulation of labor type to co-workers main introduction factor yields a chi square value of 57.97415 with 8 degrees of freedom giving a significance level of .0000 . The value of gamma was -.75492 indicating a position for dependence between labor type and introduction factor.

TABLE 34

CROSS-TABULATION OF QUESTION 5 TO QUESTION 11 LABOR TYPE TO MAIN INTRODUCTION FACTOR FOR CO-WORKERS

\begin{tabular}{c|c|c|c|c|c|c}
\hline \hline Variables & $\begin{array}{c}\text { Produc- } \\
\text { tivity }\end{array}$ & $\begin{array}{c}\text { Improve } \\
\text { Quality }\end{array}$ & $\begin{array}{c}\text { Labor } \\
\text { Costs }\end{array}$ & $\begin{array}{c}\text { Expand } \\
\text { Prod }\end{array}$ & Other & Total \\
\hline \multirow{3}{*}{ Union } & 4 & 1 & 60 & 0 & 1 & 66 \\
& 15.6 & 1.5 & 46.7 & 1.5 & .7 & \\
& -11.6 & -.5 & 13.3 & -1.5 & .3 & \\
\hline \multirow{3}{*}{ Prof } & 9 & 1 & 3 & 1 & 0 & 14 \\
& 3.3 & .3 & 9.9 & .3 & .2 & \\
& 5.7 & .7 & -6.9 & .7 & -.2 & \\
\hline \multirow{3}{*}{ Mgt } & 8 & 0 & 0 & 1 & 0 & 9 \\
& 2.1 & .2 & 6.4 & .2 & .1 & \\
\hline Total & 5.9 & -.2 & -6.4 & .8 & -.1 & \\
\hline
\end{tabular}

Note: Chi Square $=57.97415$, Degrees of Freedom $=8$, Significance Level $=.0000$, Gamma $=-.75492$

The questionnaire instrument asked the respondents to state what they believed the introduction of robots had done to the employment level of their company. The results are shown in Table 35. The table indicates that the hands-on employees believed that the employment level had decreased while support personnel and management workers believed there was no change. The data yields 
a chi square value of 23.49640 with 4 degrees of freedom giving a significance level of .0001 . The value of gamma was .92413 indicating a position for dependence between the variables.

TABLE 35

CROSS-TABULATION OF QUESTION 5 TO QUESTION 12 - LABOR TYPE TO EMPLOYMENT LEVEL

\begin{tabular}{c|c|c|c|c}
\hline \hline Variables & Decreased & No Change & Increased & Total \\
\hline \multirow{3}{*}{ Union } & 38 & 28 & 0 & 66 \\
& 28.9 & 35.6 & 1.5 & \\
& 9.1 & -7.6 & -1.5 & \\
\hline \multirow{3}{*}{ Prof } & 1 & 12 & 1 & 14 \\
& 6.1 & 7.6 & .3 & \\
& -5.1 & 4.4 & .7 & 9 \\
Mgt & 0 & 8 & 1 & \\
& 3.9 & 4.9 & .2 & .8 \\
\hline Total & -3.9 & 3.1 & 2 & 89 \\
\hline
\end{tabular}

Note: Chi Square $=23.49640$, Degrees of Freedom $=4$, Significance Level $=.0001$, Gamma $=.92413$

The respondents were asked what they believed their coworkers felt was the affect that the introduction of robots had on the employment level of their company (See Table 36). The results indicated that the perceived feelings of the co-workers were similar to the respondents beliefs concerning the employment level of their company. The chi square test had a value of 26.02450 with 2 degrees of freedom giving a significance level of .0000 . The value of gamma was .83603 indicating a position for dependence between 
labor types and the perceptions of co-workers to the employment level of the firm.

TABLE 36

CROSS-TABULATION OF QUESTION 5 TO QUESTION 13 - LABOR TYPE TO EMPLOYMENT LEVEL FOR CO-WORKERS

\begin{tabular}{c|c|c|c}
\hline \hline Variables & Decreased & No Change & Total \\
\hline \multirow{3}{*}{ Union } & 55 & 11 & 66 \\
& 45.2 & 20.8 & \\
& 9.8 & -9.8 & 14 \\
Prof & 4 & 10 & \\
& 9.6 & 4.4 & 9 \\
\hline \multirow{3}{*}{ Mgt } & -5.6 & 5.6 & \\
& 2 & 7 & 89 \\
\hline Total & 6.2 & 4.8 & \\
\hline
\end{tabular}

Note: Chi Square $=26.02450$, Degrees of Freedom $=2$, Significance Level $=.0000$, Gamma $=.83603$

The questionnaire requested a response to a statement regarding the chronic unemployment of workers due to the introduction of robots. The results of those surveyed are shown in Table 37. The value of chi square was 44.80701 with 4 degrees of freedom giving a significance level of .0000 indicating that the hands-on employees agreed with the statement while support personnel and management workers disagreed. Gamma had a value of .96364 indicating a position for dependence between the variables. 
TABLE 37

CROSS-TABULATION OF QUESTION 5 TO QUESTION 14 - LABOR TYPE TO CHRONIC EMPLOYMENT

\begin{tabular}{c|c|c|c|c}
\hline \hline Variables & Agree & Disagree & No Opinion & Total \\
\hline \multirow{3}{*}{ Union } & 53 & 13 & 0 & 66 \\
& 40.0 & 25.2 & .7 & \\
& 13.0 & -12.2 & -.7 & \\
\hline \multirow{3}{*}{ Prof } & 1 & 12 & 1 & 14 \\
& 8.5 & 5.3 & .2 & \\
& -7.5 & 6.7 & .8 & 9 \\
Mgt & 0 & 9 & 0 & \\
& 5.5 & 3.4 & .1 & 89 \\
\hline Total & -5.5 & 5.6 & -.1 & 1 \\
\hline
\end{tabular}

Note: Chi Square $=44.80701$, Degrees of Freedom $=4$, Significance Level $=.0000$, Gamma $=.96364$

Support personnel and management workers indicated that a larger percentage of their co-workers would agree with the statement regarding chronic unemployment due to the introduction of robots than they themselves (See Table 38). This indicated that support personnel and management workers felt that co-workers were perceived to be more threatened than they themselves in the previous question. The value of this chi square was 10.39759 with 4 degrees of freedom giving a significance level of .0342 , therefore the null hypothesis was rejected. It should be noted, however, that gamma had a value of only .27854 , indicating a position for independence between the variables.

The questionnaire asked the respondents to describe the reaction of employees when confronted with the introduction of 
TABLE 38

CROSS-TABULATION OF QUESTION 5 TO QUESTION 15 - LABOR TYPE TO CHRONIC EMPLOYMENT FOR CO-WORKERS

\begin{tabular}{c|c|c|c|c}
\hline \hline Variables & Agree & Disagree & No Opinion & Total \\
\hline \multirow{3}{*}{ Union } & 58 & 8 & 0 & 66 \\
& 57.1 & 8.2 & .7 & \\
& .9 & -.2 & -.7 & \\
\hline \multirow{3}{*}{ Prof } & 13 & 1 & 0 & 14 \\
& 12.1 & 1.7 & .2 & \\
& .9 & -.7 & -.2 & 9 \\
Mgt & 6 & 2 & 1 & \\
& 7.8 & 1.1 & .1 & .9 \\
\hline Total & -1.8 & .9 & 1 & 89 \\
\hline
\end{tabular}

Note: Chi Square $=10.39759$, Degrees of Freedom $=4$, Significance Level $=.0342$, Gamma $=.27854$

robots. The cross-tabulation of labor to the reaction of employees to the introduction of robots indicated that the hands-on employees felt that the introduction was negative while support personnel and management employees felt that the reaction was neutral (See Table 39). The chi square value for this cross-tabulation was 53.56531 with 8 degrees of freedom giving a significant level of .0000 . The value of gamma was .67456 indicating a position for dependence between the reactions of the work force and labor types.

The survey asked the respondents to indicate what was done to reduce worker apprehension in order to facilitate the introduction of robots into the workplace. The cross-tabulation of labor type to reducing worker apprehension showed that the hands-on employees felt that nothing was done to facilitate the introduction of robots 
TABLE 39

CROSS-TABULATION OF QUESTION 5 TO QUESTION 16 - LABOR TYPE TO EMPLOYEE REACTIONS

\begin{tabular}{|c|c|c|c|c|c|c|}
\hline Variables & Positive & Neutral & Negative & $\begin{array}{l}\text { Strongly } \\
\text { Negative }\end{array}$ & $\begin{array}{c}\text { No } \\
\text { Opinion }\end{array}$ & Total \\
\hline Union & $\begin{array}{c}0 \\
2.2 \\
-2.2\end{array}$ & $\begin{array}{c}7 \\
15.6 \\
-8.6\end{array}$ & $\begin{array}{c}46 \\
37.1 \\
8.9\end{array}$ & $\begin{array}{l}13 \\
9.6 \\
3.4\end{array}$ & $\begin{array}{c}0 \\
1.5 \\
-1.5\end{array}$ & 66 \\
\hline Prof & $\begin{array}{c}3 \\
.5 \\
2.5\end{array}$ & $\begin{array}{c}8 \\
3.3 \\
4.7\end{array}$ & $\begin{array}{c}2 \\
7.9 \\
-5.9\end{array}$ & $\begin{array}{c}0 \\
2.0 \\
-2.0\end{array}$ & $\begin{array}{l}1 \\
.3 \\
.7\end{array}$ & 14 \\
\hline $\mathrm{Mgt}$ & $\begin{array}{c}0 \\
.3 \\
-.3 \\
\end{array}$ & $\begin{array}{c}6 \\
2.1 \\
3.9 \\
\end{array}$ & $\begin{array}{c}2 \\
5.1 \\
-3.1 \\
\end{array}$ & $\begin{array}{c}0 \\
1.3 \\
-1.3 \\
\end{array}$ & $\begin{array}{l}1 \\
.2 \\
.8 \\
\end{array}$ & 9 \\
\hline Total & 3 & 21 & 50 & 13 & 2 & 89 \\
\hline
\end{tabular}

Note: Chi Square $=53.56531$, Degrees of Freedom $=8$, Significance Level $=.0000$, Gamma $=.67456$

while support personnel and management workers felt that discussion techniques were used (See Table 40). The value of chi square for this cross-tabulation had a value of 44.77019 with 10 degrees of freedom giving a significance level of .0000 . The value of gamma was -.70210 indicating a position for dependence between the variables.

The questionnaire asked the respondents to comment on whether their company had a retraining policy for displaced workers due to the introduction of robots. A chi square value of 42.10836 with 2 degrees of freedom gives a significance level of .0000 to the cross-tabulation of labor type to the existence of a retraining policy for the company. Table 41 shows that the hands-on employees 
TABLE 40

CROSS-TABULATION OF QUESTION 5 TO QUESTION 17 - LABOR TYPE TO FACILITATE INTRODUCTION

\begin{tabular}{c|c|c|c|c|c|c|c}
\hline \hline $\begin{array}{c}\text { Vari- } \\
\text { ables }\end{array}$ & $\begin{array}{c}\text { Dis- } \\
\text { cussion }\end{array}$ & $\begin{array}{c}\text { Skill } \\
\text { Training }\end{array}$ & $\begin{array}{c}\text { Partici- } \\
\text { pation }\end{array}$ & $\begin{array}{c}\text { Notify } \\
\text { Union }\end{array}$ & None & $\begin{array}{c}\text { No } \\
\text { Opinion }\end{array}$ & Total \\
\hline \multirow{3}{*}{ Union } & 4 & 1 & 5 & 3 & 52 & 1 & 66 \\
& 11.9 & 2.2 & 4.4 & 5.2 & 40.8 & 1.5 & \\
& -7.9 & -1.2 & .6 & -2.2 & 11.2 & -.5 & \\
\hline \multirow{3}{*}{ Prof } & 8 & 1 & 0 & 2 & 3 & 0 & 14 \\
& 2.5 & .5 & .9 & 1.1 & 8.7 & .3 & \\
& 5.5 & .5 & -.9 & .9 & -5 & -.3 .7 & \\
\hline \multirow{3}{*}{ Mgt } & 4 & 1 & 1 & 2 & 0 & 1 & 9 \\
& 1.6 & .3 & .6 & .7 & 5.6 & .2 & \\
\hline Total & 2.4 & .7 & .4 & 1.3 & -5.6 & .8 & \\
\hline
\end{tabular}

Note: Chi Square $=44.77019$, Degrees of Freedom $=10$, Significance Level $=.0000$, Gamma $=-.70210$

believe there was no training policy while support personnel and management felt that one existed. The value of gamma was -.93870 indicating a position for dependence between the variables. There was not a cross-tabulation of labor type to the use of the training policy due to the low number of affirmative responses to the previous question.

The questionnaire asked the respondents to state what they believed their co-workers felt regarding whether the company had a retraining policy for those employees replaced by the introduction of robots. In the cross-tabulation of the perception of what co-workers felt to the company having a retraining policy, the hands-on employees felt that their co-workers also believed there was no such 
TABLE 41

CROSS-TABULATION OF QUESTION 5 TO QUESTION 18 - LABOR TYPE TO TRAINING POLICY

\begin{tabular}{c|c|c|c}
\hline \hline Variables & Yes & No & Total \\
\hline \multirow{3}{*}{ Union } & 7 & 59 & 66 \\
& 18.5 & 47.5 & \\
\hline \multirow{3}{*}{ Prof } & -11.5 & 11.5 & 14 \\
& 9 & 5 & \\
\hline \multirow{3}{*}{ Mgt } & 3.9 & 10.1 & 9 \\
& 5.1 & -5.1 & \\
\hline Total & 9.5 & 6.5 & 89 \\
\hline
\end{tabular}

Note: Chi Square $=42.10836$, Degrees of Freedom $=2$, Significance Level $=.0000$, Gamma $=-.93870$

retraining policy while support personnel and management employees felt that their co-workers believed that it existed (See Table 42). The chi square statistic had a value of 49.24263 with 4 degrees of freedom giving a significance level of .0000 . The value of gamma was -.78245 indicating a position for dependence between the variables. Again, there was no cross-tabulation of co-worker labor types to the use of the training policy due to the low number of affirmative responses to the previous question.

The survey instrument asked the respondents to indicate the degree of responsibility that the individual, company, education, government and unions had in the retraining of employees displaced by robots. The only chi square with a significant value in the crosstabulation of labor type to retraining responsibility was that of the 
TABLE 42

CROSS-TABULATION OF QUESTION 5 TO QUESTION 20 - LABOR TYPE TO TRAINING POLICY FOR CO-WORKERS

\begin{tabular}{c|c|c|c|c}
\hline \hline Variables & Yes & No & No Opinion & Total \\
\hline \multirow{3}{*}{ Union } & 3 & 63 & 0 & 66 \\
& 13.3 & 51.9 & .7 & \\
& -10.3 & 11.1 & -.7 & \\
\hline \multirow{3}{*}{ Prof } & 9 & 5 & 0 & 14 \\
& 2.8 & 11.0 & .2 & \\
& 6.2 & -6.0 & -.2 & 9 \\
Mgt & 6 & 2 & 1 & .1 \\
\hline Total & 1.8 & 7.1 & .9 & 89 \\
\hline
\end{tabular}

Note: Chi Square $=49.24263$, Degrees of Freedom $=4$, Significance Level $=.0000$, Gamma $=-.78245$

responsibility of the company. This chi square had a value of 20.96462 with 4 degrees of freedom giving a significance level of .0003 . The hands-on employees members believed that the company had a maximum role in the retraining responsibility while support personnel and management employees felt the company played a moderate role (See Table 43). The value of gamma was .40514 indicating a weak position for dependence between labor type and the role of the company in retraining employees.

The cross-tabulation for the safety and health hazards of a company was not significant, however, the cross-tabulation for the health and safety of the respondent's company had a chi square of 27.09091 with 2 degrees of freedom giving a significance level of .0000 . As shown in Table 44, the hands-on employees indicated that 
TABLE 43

CROSS-TABULATION OF QUESTION 5 TO QUESTION 22 - LABOR TYPE TO RETRAINING RESPONSIBILITY - COMPANY

\begin{tabular}{c|c|c|c|c}
\hline \hline Variables & Minimum & Moderate & Maximum & Total \\
\hline \multirow{3}{*}{ Union } & 8 & 9 & 49 & 66 \\
& 5.9 & 17.1 & 43.0 & \\
& 2.1 & -8.1 & 6.0 & \\
\hline \multirow{3}{*}{ Prof } & 0 & 9 & 5 & 14 \\
& 1.3 & 3.6 & 9.1 & \\
\hline \multirow{3}{*}{ Mgt } & -1.3 & 5.4 & -4.1 & 9 \\
& 0 & 5 & 4 & \\
\hline Total & .8 & 2.3 & 5.9 & 89 \\
\hline
\end{tabular}

Note: Chi Square $=20.96462$, Degrees of Freedom $=4$, Significance Level $=.0003$, Gamma $=-.40514$

robots did not and would not reduce the safety and health hazards of their company while support personnel and management employees felt otherwise. Gamma had a value of -.84736 indicating a position for dependence between the variables.

The cross-tabulation of labor to robots making a company more competitive had a chi square of 24.70411 with 2 degrees of freedom giving a significance level of .0001 (See Table 45). This indicates that the hands-on employees had mixed feelings toward competition while support personnel and management employees felt overwhelmingly that robots could make a company more competitive. The value of gamma was -.74005 indicating a position for dependence between the variables. 
TABLE 44

CROSS-TABULATION OF QUESTION 5 TO QUESTION 24 - LABOR TYPE TO SAFETY AND HEALTH HAZARDS OF EMPLOYEE'S COMPANY

\begin{tabular}{c|c|c|c}
\hline \hline Variables & Yes & No & Total \\
\hline \multirow{3}{*}{ Union } & 10 & 56 & 66 \\
& 19.3 & 46.7 & \\
\hline \multirow{3}{*}{ Prof } & -9.3 & 9.3 & 14 \\
& 8 & 6 & \\
\hline \multirow{3}{*}{ Mgt } & 4.1 & 9.9 & 9 \\
& 3.9 & -3.9 & \\
\hline Total & 2.6 & 1 & 8.4 \\
\hline
\end{tabular}

Note: Chi Square $=27.09091$, Degrees of Freedom $=2$, Significance Level $=.0000$, Gamma $=-.84736$

TABLE 45

CROSS-TABULATION OF QUESTION 5 TO QUESTION 25 - LABOR TYPE TO COMPETITION OF A COMPANY

\begin{tabular}{c|c|c|c|c}
\hline Variables & Yes & No & No Opinion & Total \\
\hline \multirow{3}{*}{ Union } & 31 & 35 & 0 & 66 \\
& 38.6 & 26.7 & .7 & \\
& -7.6 & 8.3 & -.7 & \\
\hline \multirow{3}{*}{ Prof } & 13 & 1 & 0 & 14 \\
& 8.2 & 5.7 & .2 & \\
\hline \multirow{3}{*}{ Mgt } & 4.8 & -4.7 & -.2 & 9 \\
& 5.3 & 0 & 1 & .1 \\
\hline Total & 2.7 & -3.6 & .9 & 89 \\
\hline
\end{tabular}

Note: Chi Square $=24.70411$, Degrees of Freedom $=2$, Significance Level $=.0001$, Gamma $=-.74005$ 
The last question in the survey instrument asked respondents if robots had made their company more competitive. The crosstabulation showed that the hands-on employees felt that robots had not made their company competitive while support personnel and management employees felt they had. The chi square had a value of 46.38306 with 4 degrees of freedom giving a significance level of .0000 (See Table 46). The value of gamma for this cross-tabulation was -.74632 indicating a position for dependence between the variables.

TABLE 46

CROSS-TABULATION OF QUESTION 5 TO QUESTION 26 - LABOR TYPE TO COMPETITION OF EMPLOYEE'S COMPANY

\begin{tabular}{c|c|c|c|c}
\hline \hline Variables & Yes & No & No Opinion & Total \\
\hline \multirow{3}{*}{ Union } & 4 & 62 & 0 & 66 \\
& 14.1 & 51.2 & .7 & \\
& -10.1 & 10.8 & -.7 & \\
\hline \multirow{3}{*}{ Prof } & 10 & 4 & 0 & 14 \\
& 3.0 & 10.9 & .2 & \\
\hline \multirow{3}{*}{ Mgt } & 7.0 & -6.9 & -.2 & 9 \\
& 5 & 3 & 1 & \\
\hline Total & 1.9 & 7.0 & .1 & .9 \\
\hline
\end{tabular}

Note: Chi Square $=46.38306$, Degrees of Freedom $=4$, Significance Level $=.0000$, Gamma $=-.74632$ 


\section{CHAPTER V}

\section{SUMMARY AND RECOMMENDATIONS}

\section{Introduction}

This last chapter provides conclusions that were drawn from the findings in Chapter IV and compares these findings to the research hypotheses. The purpose of the research was to examine the effect that the introduction of an advanced manufacturing technology, specifically robotics, had on the work force of an aerospace defense company. The two main objectives were to determine if workers felt threatened by the introduction of robotic technology and to compare the degree to which workers from different labor types felt this threat.

\section{The Results of Hypothesis Testing}

The results of the questionnaire survey are compared to the research hypotheses in Table 47 . This table matches the survey to each postulated hypothesis in this dissertation.

The two main objectives of this dissertation, determining the threat of worker's job security due to the introduction of robots and the degree to which workers from different labor types feel this threat, were examined by comparing the findings of the literature review to the questionnaire results.

The first hypothesis states that job security is highest for 
TABLE 47

COMPARISON OF SURVEY RESULTS TO RESEARCH HYPOTHESES

\begin{tabular}{|c|c|c|}
\hline $\begin{array}{c}\text { Research } \\
\text { Hypotheses }\end{array}$ & $\begin{array}{c}\text { Survey } \\
\text { Questions } \\
\end{array}$ & $\begin{array}{l}\text { Sign. } \\
\text { Level } \\
\end{array}$ \\
\hline $\begin{aligned} \mathrm{H}_{1}= & \text { Job security is highest for employees who } \\
& \text { are furthermost from the robotic technology } \\
& \text { (support personnel and management), with } \\
& \text { such security decreasing as workers are } \\
& \text { brought into closer contact with robots } \\
& \text { (hands-on). }\end{aligned}$ & $\begin{array}{c}\text { Question } 5 \\
\text { to } \\
\text { Question } 8 \\
\text { Question } 9\end{array}$ & $\begin{array}{l}.0000 \\
.0000\end{array}$ \\
\hline $\begin{aligned} \mathrm{H} 2= & \text { Workers closer to the robotic technology } \\
& \text { (hands-on) perceive that the lowering of } \\
& \text { labor costs is the major factor prompting } \\
& \text { the introduction of robotics into their } \\
& \text { company while workers more removed } \\
& \text { from robotics (support personnel and } \\
& \text { management) believe other factors are } \\
& \text { more important. }\end{aligned}$ & $\mid \begin{array}{cc}\text { Question } & 5 \\
\text { to } & \\
\text { Question } & 10 \\
\text { Question } & 11\end{array}$ & $\begin{array}{l}.0000 \\
.0000\end{array}$ \\
\hline $\begin{aligned} \mathrm{H}_{3}= & \text { Workers closer to the robotic technology } \\
& \text { (hands-on) perceive that robots have } \\
& \text { decreased the employment level in their } \\
& \text { company while workers more removed } \\
& \text { from robotics (support personnel and } \\
& \text { management) believe that employment } \\
& \text { within their company has not changed or } \\
& \text { has even increased. }\end{aligned}$ & $\left|\begin{array}{cc}\text { Question } & 5 \\
\text { to } & \\
\text { Question } & 12 \\
\text { Question } & 13\end{array}\right|$ & $\begin{array}{l}.0001 \\
.0000\end{array}$ \\
\hline $\begin{aligned} \mathrm{H}_{4}= & \text { Workers closer to the robotic technology } \\
& \text { (hands-on) agree that the increased usage } \\
& \text { of robots will cause chronic unemployment } \\
& \text { while workers more removed from robotics } \\
& \text { (support personnel and management) } \\
& \text { disagree that robotics applications will } \\
& \text { result in chronic unemployment. }\end{aligned}$ & $\left|\begin{array}{cc}\text { Question } & 5 \\
\text { to } & \\
\text { Question } & 14 \\
\text { Question } & 15\end{array}\right|$ & $\begin{array}{l}.0000 \\
.0342\end{array}$ \\
\hline
\end{tabular}


TABLE 47 (Continued)

COMPARISON OF SURVEY RESULTS TO RESEARCH HYPOTHESES

\begin{tabular}{|c|c|c|c|}
\hline & $\begin{array}{c}\text { Research } \\
\text { Hypotheses } \\
\end{array}$ & $\begin{array}{c}\text { Survey } \\
\text { Questions }\end{array}$ & $\begin{array}{l}\text { Sign. } \\
\text { Level } \\
\end{array}$ \\
\hline $\mathrm{H} 5=$ & $\begin{array}{l}\text { Workers closer to the robotic technology } \\
\text { (hands-on) perceive that the reaction of } \\
\text { employees to robots is negative or strongly } \\
\text { negative while workers more removed from } \\
\text { robotics (support personnel and manage- } \\
\text { ment) believe that employee reaction } \\
\text { to robots is positive or very positive. }\end{array}$ & $\left|\begin{array}{cc}\text { Question } & 5 \\
\text { to } & \\
\text { Question } & 16\end{array}\right|$ & .0000 \\
\hline$\overline{\mathrm{H} 6=}$ & $\begin{array}{l}\text { Workers closer to the robotic technology } \\
\text { (hands-on) perceive that there was no } \\
\text { effort to reduce worker apprehension to } \\
\text { the introduction of robots while workers } \\
\text { more removed from robotics (support } \\
\text { personnel and management) believe that } \\
\text { several methods were used. }\end{array}$ & $\left|\begin{array}{cc}\text { Question } & 5 \\
\text { to } & \\
\text { Question } & 17\end{array}\right|$ & .0000 \\
\hline $\mathrm{H}_{7}=$ & $\begin{array}{l}\text { Workers closer to the robotic technology } \\
\text { (hands-on) perceive that the firm has no } \\
\text { retraining policy with regard to the } \\
\text { implementation of robots while workers } \\
\text { more removed from robotics (support } \\
\text { personnel and management) believe that } \\
\text { such a policy exists. }\end{array}$ & $\begin{array}{|cc|}\text { Question } & 5 \\
\text { to } & \\
\text { Question } & 18 \\
\text { Question } & 19 \\
\text { Question } & 20 \\
\text { Question } & 21\end{array}$ & $\begin{array}{l}.0000 \\
\text { None } \\
.0000 \\
\text { None }\end{array}$ \\
\hline$\overline{\mathrm{H} 8=}$ & $\begin{array}{l}\text { Workers closer to the robotic technology } \\
\text { (hands-on) believe that the union should } \\
\text { have a larger degree of responsibility in } \\
\text { training employees displaced by robots } \\
\text { while workers more removed from robotics } \\
\text { (support personnel and management) } \\
\text { believe that unions should not. }\end{array}$ & $\begin{array}{c}\text { Question } 5 \\
\text { to } \\
\text { Question } 22 \\
\text { Individual } \\
\text { Company } \\
\text { Education } \\
\text { Government } \\
\text { Union } \\
\end{array}$ & $\begin{array}{l}.7098 \\
.0003 \\
.1407 \\
.4802 \\
.0565 \\
\end{array}$ \\
\hline
\end{tabular}


TABLE 47 (Continued)

COMPARISON OF SURVEY RESULTS TO RESEARCH HYPOTHESES

\begin{tabular}{|c|c|c|}
\hline $\begin{array}{c}\text { Research } \\
\text { Hypotheses }\end{array}$ & $\begin{array}{c}\text { Survey } \\
\text { Questions }\end{array}$ & $\begin{array}{l}\text { Sign. } \\
\text { Level }\end{array}$ \\
\hline $\begin{aligned} \mathrm{H} 9= & \text { Workers closer to the robotic technology } \\
& \text { (hands-on) believe that robots do not } \\
& \text { reduce the safety and health hazards while } \\
& \text { workers more removed from robotics } \\
& \text { (support personnel and management) } \\
& \text { believe that they do. }\end{aligned}$ & $\begin{array}{c}\text { Question } \\
\text { to } \\
\text { Question } \\
\text { Question } \\
\text { Qu }\end{array}$ & $\begin{array}{l}.1603 \\
.0000\end{array}$ \\
\hline $\begin{aligned} \mathrm{H}_{10}= & \text { Workers closer to the robotic technology } \\
& \text { (hands-on) believe that robots do not make } \\
& \text { the firm more competitive while workers } \\
& \text { more removed from robotics (support } \\
\text { personnel and management) believe that } & \text { they do. }\end{aligned}$ & $\begin{array}{cc}\text { Question } & 5 \\
\text { to } & \\
\text { Question } & 25 \\
\text { Question } & 26\end{array}$ & $\begin{array}{l}.0001 \\
.0000\end{array}$ \\
\hline
\end{tabular}

employees who are furthermost from the robotic technology (support personnel and management), with such security decreasing as workers are brought into closer contact with robots (hands-on personnel). The literature review indicated there is disagreement whether or not the introduction of robots will result in widespread displacement of workers. Additionally, it was shown there has been little emphasis on the human factor with regard to the introduction of technology into the work place. The literature indicates there is some evidence that the work force does believe that technology is detrimental to their job security. It was further noted that reasons other than the threat to job security accounted for workers fearing or resenting the introduction of robotics. These reasons included the perception of an increased workload, loss of status, loss of prestige 
and the lack of perceived expertise. However, the literature review indicated that the root of worker fears concerning the introduction of robots is the loss of employment; therefore, job security was assumed to be the major factor in this study of workers within an aerospace defense company.

The questionnaire results showed that the introduction of robots in one aerospace defense company was seen as threatening the job security of employees to some degree. Robots were viewed as more of a threat to the job security of the hands-on worker than to support personnel or management and therefore supported the research hypothesis. The results further indicated that the hands-on respondents perceive that their co-workers had a higher threat to. job security than support personnel or managers.

The findings of the first hypothesis may have significant implications for the major threat facing industries today, the need to increase productivity in order to survive in world markets. If the findings in this study are representative of companies within the United States, then questions may arise as to the impact that the perceived threat to worker job security would have on impeding the progress necessary for that survival. Would worker resistance to the introduction of advanced technology be a key determinant in the United States' role in world manufacturing? Is the quest for survival sufficient to drive corporations and businesses to the point of introducing advanced manufacturing technologies regardless of the portentously detrimental effect on the work force? It would appear 
from the results of this study that these issues are worthy of serious consideration.

The remaining hypotheses were postulated in order to search for any secondary issues present within the aerospace defense company. These hypotheses were outside the two main objectives of this dissertation and beyond the subject research survey; therefore, their application is limited to the findings of the questionnaire analysis.

Hypothesis number two states that workers closer to the robotic technology (hands-on personnel) perceive that the lowering of labor costs is the major factor prompting the introduction of robotics into their company while workers more removed from robotics (support personnel and management) believe other factors are more important. The results indicated that union members or hands-on employees believed that the lowering of labor costs was the major factor in the introduction of robots while support personnel and managers believed the major factor for the introduction was increasing productivity. The respondents further indicated that the hands-on employees stated that their co-workers also believed lowering labor costs was the main factor in the introduction of robotics while support personnel and management co-workers believe that it was due to increasing productivity. Therefore, the results support the hypothesis.

The third hypothesis stated that workers closer to the robotic technology (hands-on personnel) perceive that robots have 
decreased the employment level in their company while workers more removed from robotics (support personnel and management) believe that employment within their company had not changed or had even increased. The results indicated that the hands-on workers believed that the employment level had decreased while support personnel and management workers believed there was no change. The data further indicated that the perceived feelings of the coworkers were similar to the respondents' belief toward the employment level of their company. Therefore, the results of the survey support the hypothesis.

The next hypothesis stated that workers closer to the robotic technology (hands-on personnel) agree that robots will cause chronic unemployment while workers more removed from robotics (support personnel and management) disagree that robotics applications will result in chronic unemployment. The results of those surveyed indicated that hands-on workers agreed with the statement while support personnel and management workers disagreed. It was noted that support personnel and management workers believed that more of their co-workers would agree with the statement regarding chronic unemployment due to the introduction of robots indicating that the co-workers were perceived to be more threatened than the respondents themselves. The hypothesis was supported by the findings of the study.

Hypothesis number five stated that workers closer to the robotic technology (hands-on personnel) perceive that the reaction of 
employees to robots is negative or strongly negative while workers more removed from robotics (support personnel and management) believe that employee reaction to robots is positive or very positive. The cross-tabulation of labor type to the reaction of employees to the introduction of robots supported part of the hypothesis as it was found that hands-on workers felt that the introduction was negative while support personnel and management employees felt that the reaction was neutral.

The sixth hypothesis stated that workers closer to the robotic technology (hands-on personnel) perceive that there was no effort to reduce worker apprehension to the introduction of robots while workers more removed from robotics (support personnel and management) believe that several methods were used. The results of cross-tabulating labor type to reducing worker apprehension indicated that hands-on workers felt that nothing was done to facilitate the introduction of robots while support personnel and management workers felt, for the most part, that discussion techniques were utilized. A reason for this disparity could be that discussion techniques were used for support personnel and management in those efforts associated with changes in their work environment, and as such, they believe that this policy is carried throughout the company. In fact, there was no evidence found to indicate that discussion techniques were used to facilitate the introduction of robots in the observed company. Only part of the hypothesis postulated was supported by the survey as the majority 
of support personnel and management selected only one technique in facilitating the introduction of robots rather than split among several methods.

The next hypothesis stated that workers closer to the robotic technology (hands-on personnel) perceive that the firm has no retraining policy with regard to the implementation of robots while workers more removed from robotics (support personnel and management) believe that such a policy exists. The results show that the hands-on employees believed there was no retraining policy while support personnel and management felt that one existed. There was no cross-tabulation of labor type to the use of the retraining policy due to chi square limitation on sample size. The results indicated that the hands-on employees felt that their coworkers also believed there was no such retraining policy while support personnel and management employees felt that their coworkers believed that it existed. There was no written evidence found that showed the company did indeed have a retraining policy, however, the company did retrain workers in similar situations in the past. There was not a cross-tabulation of co-worker labor types to the use of the retraining policy due to chi square limitations, therefore, the results of the survey support the hypothesis.

Hypothesis number eight stated that workers closer to the robotic technology (hands-on personnel) believe that the union should have a larger degree of responsibility in training employees displaced by robots while workers more removed from robotics 
(support personnel and management) believe that unions should not. However, the only chi square with a significant value in the crosstabulation of labor type to retraining responsibility was that of the responsibility of the company. In this cross-tabulation, the hands-on employees believed that the company had a major role in the retraining responsibility while support personnel and management employees felt the company played a moderate role. Therefore, the results of the questionnaire survey did not support the hypothesis.

The ninth hypothesis stated that workers closer to the robotic technology (hands-on personnel) believe that robots do not reduce the safety and health hazards while workers more removed from robotics (support personnel and management) believe that they do. The cross-tabulation for the safety and health hazards of a company was not found to be significant, however, the cross-tabulation for the health and safety of the respondent's company indicated that handson workers felt that robots did not and would not reduce the safety and health hazards of their company while support personnel and management employees felt otherwise. The results of the survey support the hypothesis, however, it should be noted that there have been no major safety issues concerning the aerospace defense company and robots were placed in situations not affected by safety considerations.

The last hypothesis stated that workers closer to the robotic technology (hands-on personnel) believe that robots do not make the firm more competitive while workers more removed from robotics 
(support personnel and management) believe that they do. The results of the cross-tabulation indicates that hands-on workers had mixed feelings toward competition benefitting companies as a whole while support personnel and management employees felt overwhelmingly that robots could make a company more competitive. The results supported the hypothesis as the hands-on workers felt that robots had not made their company competitive while support personnel and management employees felt otherwise.

Topics for Further Research

This dissertation examined the effect of the introduction of robotics on one aerospace defense company. Only one company was examined, therefore, there should be additional research is required to ascertain if similar results from other companies as well as other industries confirm the hypotheses stated herein.

One notable and potentially fruitful area of examination encompasses the role that unions play in the introduction of advanced manufacturing technology. Such an analysis should examine whether hands-on employees feel that their job security is threatened due to their proximity to the work, as this dissertation claims, or whether the membership in a union is a determinant. Additional studies could be performed using non-union companies and the results compared to the findings of this dissertation to ascertain what impact membership in a union would have on the threat of robots to the job security of the work force. 
Another conceivably productive area of further research involves the analysis of the demographic characteristics of the work force to determine if there is any discriminant, such as age and gender, tying the perceptions of the work force to the introduction of advanced manufacturing technologies. This area of demographic examination may be expanded to include a contrast of cultures such as comparing the introduction of advanced manufacturing technologies in the United States to introductions in foreign countries.

Additional studies would be required to formulate the necessary criteria for defining what constitutes success and what constitutes failure in integrating technology into the manufacturing environment. An integrated approach to the introduction of advanced manufacturing technologies could aid both theoreticians and practitioners by creating new paradigms outlining the successful interface between man and machines.

\section{Summary}

The first objective of this dissertation was to determine if workers at an aerospace defence company felt threatened by the introduction of robotic technology. It was found that robots did threaten the job security of over seventy-eight percent of the workers surveyed to some degree.

The second objective was to compare the degree to which workers from different labor types felt this threat. It was found that the introduction of robotics into one aerospace defense company was 
seen as more of a threat to the job security of the hands-on employees than to support personnel or management.

The intention of this study is to give insight to those individuals interested in the successful integration of advanced manufacturing technologies and the work force. It is hoped that this dissertation has provided a better understanding of the impacts of robotics on the work force and the reaction of employees in three separate labor types (hands-on operator, support personnel, and management) within an aerospace defense environment. 
APPENDIX A

PARTICIPANT LETTER 
May 13, 1988

Dear Participant:

You have been selected to participate in a study involving the introduction and use of robotic technology and its effect on the workplace. As a doctoral student at North Texas State University, I have chosen this subject as the topic for my dissertation. I believe that with your help, the results will aid in a better understanding of the effect of technology on manufacturing industries.

I would appreciate you taking the time to fill out the questionnaire as it should only take a few minutes to complete. Your participation is critical to the success of this research as the number of returns is important to the validity of the study.

Please seal your completed questionnaire in the envelop provided. This will ensure that your response will be treated confidentially. If you desire a copy of the study results, please write your name and address on the results form in order to preserve your anonymity.

Thank you for your help.

Sincerely Yours,

William B. Rose, Jr.

Encl.: Questionnaire Envelope 
APPENDIX B

QUESTIONNAIRE

104 


\section{QUESTIONNAIRE}

The responses to this questionnaire will be used as a basis of research for graduate studies. All responses will be held confidential. Please answer the following.

\section{PART I - GENERAL}

1. Please indicate your gender. male

_ female

2. Please indicate your age.

- 20 years and under

— 21 years to 30 years

- 31 years to 40 years

- 41 years to 50 years

— 51 years and older

3. How many years have you been employed with the company?

_ 5 years or less

_ 6 years to 10 years

- 11 years to 15 years

- 16 years to 20 years

- 21 years to 25 years

— 26 years or more

4. How many years have you worked at your present position within the company?
- 1 year or less
- 2 years to 3 years
- 4 years to 5 years
- 6 years to 7 years
- 8 years to 9 years
- 10 years or more

5. What is your present labor type within the company? (please check only one) union professional management 6. What is your education level? (please check only one)
no high school some high school high school degree some college - college degree some post graduate post graduate degree 
For the purpose of this survey, the following definition will be used:

"A robot is a reprogrammable multi-functional manipulator designed to move materials, parts, tools, and specialized devices through variable
programmed motions for the performance of a variety of tasks."

7. Your company: (please check one) uses robots

- does not use and does not plan to use robots

_ plans to use robots If your company does not use and does not plan to use robots, please stop
here.

\section{PART II - JOB SECURITY}

8. In your opinion, what level of threat to your job security have you felt from the introduction of robots in your company? (please check one)

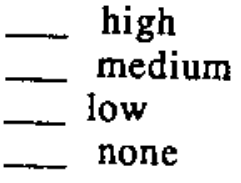

9. Please answer what you believe that your co-workers would answer to the threat of their job security to the introduction of robots in your company. (please check one)

_ high

__ medium

- low

- none

10. What do you believe was the major factor that prompted the introduction of robots in the company? (please check one) _._. increasing productivity

__ improving product quality

- reducing safety and health hazards

_ lowering labor costs

-_- expanding total production

other (please specify) - no opinion 
11. What do you believe your co-workers feel was the major factor

that prompted the introduction of robots in the company?
(please check one)

-_ increasing productivity

_ improving product quality

- reducing safety and health hazards

_ lowering labor costs

- expanding total production

— other (please specify)

— no opinion

12. In your opinion, how did the introduction of robots affect the employment level in the company?

- decreased employment

-_ no change in employment

-_ increased employment

- no opinion

13. Please indicate what you believe your co-workers would answer on the introduction of robots affecting the employment level in the company.

- decreased employment

- no change in employment

- increased employment

__ no opinion

14. Please respond to the following statement. A high level of chronic unemployment among displaced workers will result from increased usage of robots.

-_ agree

- disagree

_ no opinion

15. Regarding question number 14, do you believe that your coworkers believe as you do? yes

no

no opinion

16. In your opinion, what has been the reaction of employees when confronted with the introduction of robots in the workplace? (please check one)

_._. strongly positive

positive

_-_ neutral

- negative

- strongly negative

__ no opinion 
17. In terms of reducing worker apprehension, what do you believe was done to facilitate the introduction of robots into the workplace? discussion and/or explanatory techniques skill training

- participative involvement in planning or implementation

- notification to worker or union

- other (please specify)

- no opinion

\section{PART III - TRAINING}

18. Do you believe that your company has a policy calling for the retraining of displaced workers for employment elsewhere in the
company?

—- yes

- no

— no opinion

19. If the answer to the previous question was yes, please indicate whether or not you believe that the policy was implemented.

— yes

- no

_._ no opinion

20. Do you believe that your co-workers believe that your company has a policy calling for the retraining of displaced workers for employment elsewhere in the company?

- yes

- no

— no opinion

21. If the answer to the previous question was yes, please indicate whether or not you believe that your co-workers believe that the policy was implemented.

— yes

— no

_ no opinion

22. What degree of responsibility do you believe that each of the following should have in retraining employees displaced by robots? Use (1) for minimum, (2) for moderate or (3) for maximum. (please place a number by each of the following)

— individual

\footnotetext{
- company

- education

_- unions

_- other (please specify)
} 


\section{PART IV - COMPETITION AND SAFETY}

23. Do you believe that robots can reduce the safety and health hazards of a company? yes

_ no

- no opinion

24. Do you believe that robots reduced or will reduce the safety and health hazards of your company? yes

_ no

- no opinion

25. Do you feel that robots can make a company more competitive?

- yes

— no

_ no opinion 26. Do you feel that robots have made or will make your company
more competitive?

_- yes

- no

__ no opinion 


\section{APPENDIX C}

QUESTIONNAIRE ANALYSIS 


\section{QUESTIONNAIRE ANALYSIS}

This questionnaire analysis will be used as the survey key used to input the data into the SPSSx statistical model. The first three columns will be used for identification purposes while the remainder of the responses will be noted as follows;

\section{PART I - GENERAL}

1. Please indicate your gender. (COLUMN 4) -1_ male

_2_ female

2. Please indicate your age. (COLUMN 5) -1_ 20 years and under

_2 21 years to 30 years

-3 31 years to 40 years

-4_ 41 years to 50 years

_5 51 years and older 3. How many years have you been employed with the company?
(COLUMN 6)

-1 5 years or less

- 2 6 years to 10 years

-3 11 years to 15 years

-4 16 years to 20 years

-5. 21 years to 25 years

_6 26 years or more

4. How many years have you worked at your present position within the company? (COLUMN 7)

_1_ 1 year or less

-2 2 years to 3 years

3. 4 years to 5 years

-4_ 6 years to 7 years

_5_ 8 years to 9 years

_6_ 10 years or more

5. What is your present labor type within the company? (please check only one) (COLUMN 8)

- 1_ union

2_ professional

_3_ management 
6. What is your education level? (please check only one) (COLUMN 9)

-1 no high school

_2_ some high school

-3_ high school degree

-4_ some college

-5_ college degree

_6_ some post graduate

_ ${ }_{\text {- }}$ post graduate degree

For the purpose of this survey, the following definition will be used:

"A robot is a reprogrammable multi-functional manipulator designed to move materials, parts, tools, and specialized devices through variable programmed motions for the performance of a variety of tasks."

7. Your company: (please check one) (COLUMN 10)

-1_ uses robots

2- does not use and does not plan to use robots

3. plans to use robots

If your company does not use and does not plan to use robots, please stop here.

\section{PART II - JOB SECURITY}

8. In your opinion, what level of threat to your job security have you felt from the introduction of robots in your company? (please check one) (COLUMN 11)

-1_ high

2- medium

3_ low

-4 none

9. Please answer what you believe that your co-workers would answer to the threat of their job security to the introduction of robots in your company. (please check one) (COLUMN 12) -1_ high

2- medium

3_ low

${ }_{-}^{4}$ - none

10. What do you believe was the major factor that prompted the introduction of robots in the company? (please check one) (COLUMN 13)

-1_ increasing productivity

-2_ improving product quality

3. reducing safety and health hazards

-4_ lowering labor costs

-5_ expanding total production

6_ other (please specify) 
_7_ no opinion

11. What do you believe your co-workers feel was the major factor that prompted the introduction of robots in the company?

(please check one) (COLUMN 14)

-1_ increasing productivity

_2_ improving product quality

-3 _ reducing safety and health hazards

-4_ lowering labor costs

-5_ expanding total production

6_ other (please specify)

_7 no opinion

12. In your opinion, how did the introduction of robots affect the employment level in the company? (COLUMN 15)

1_ decreased employment

2_ no change in employment

3 3 increased employment

-4_ no opinion

13. Please indicate what you believe your co-workers would answer on the introduction of robots affecting the employment level in the company. (COLUMN 16)

-1_ decreased employment

2_ no change in employment

-3

4_ no opinion

14. Please respond to the following statement. A high level of chronic unemployment among displaced workers will result from increased usage of robots. (COLUMN 17)

-1_ agree

_2. disagree

3 3 no opinion

15. Regarding question number 14 , do you believe that your coworkers believe as you do? (COLUMN 18)

-1 - yes

2_ no

3_ no opinion

16. In your opinion, what has been the reaction of employees when confronted with the introduction of robots in the workplace? (please check one) (COLUMN 19)

1_ strongly positive

2_ positive

3_ neutral

-4_ negative

_. 5 strongly negative

6_ no opinion 
17. In terms of reducing worker apprehension, what do you believe was done to facilitate the introduction of robots into the workplace? (COLUMN 20)

-1_ discussion and/or explanatory techniques

2_ skill training

3. participative involvement in planning or implementation

-4_ notification to worker or union

-5 _ none

-6_ other (please specify)

-7_ no opinion

\section{PART III - TRAINING}

18. Do you believe that your company has a policy calling for the retraining of displaced workers for employment elsewhere in the company? (COLUMN 21)

-1 - yes

${ }^{2}-$ no

3_ no opinion

19. If the answer to the previous question was yes, please indicate whether or not you believe that the policy was implemented. (COLUMN 22)

-1_yes

-2_ no

3_ no opinion

20. Do you believe that your co-workers believe that your company has a policy calling for the retraining of displaced workers for employment elsewhere in the company? (COLUMN 23)

-1 - yes

2- no

3- no opinion

21. If the answer to the previous question was yes, please indicate whether or not you believe that your co-workers believe that the policy was implemented. (COLUMN 24)

-1_ yes

2. no

-3_ no opinion 
22. What degree of responsibility do you believe that each of the following should have in retraining employees displaced by robots? Use (1) for minimum, (2) for moderate or (3) for maximum. (please place a number by each of the following) -1,2,3_ individual (COLUMN 25)

$-1,2,3$ _ company (COLUMN 26)

$-1,2,3$ _ education (COLUMN 27)

$-1,2,3$ _ govemment (COLUMN 28)

_ 1,2,3_ unions (COLUMN 29)

$0,1,2,3$ other (please specify) (COL,UMN 30)

\section{PART IV - COMPETITION AND SAFETY}

23. Do you believe that robots can reduce the safety and health hazards of a company? (COLUMN 31)

-1 - yes

2_ no

3_ no opinion

24. Do you believe that robots reduced or will reduce the safety and health hazards of your company? (COLUMN 32)

-1 - yes

-2 - no

3_ no opinion

25. Do you feel that robots can make a company more competitive? (COLUMN 33)

-1 - yes

-2_ no

3_ no opinion

26. Do you feel that robots have made or will make your company more competitive? (COLUMN 34)

-1 - yes

-2 no

3_ no opinion 


\section{BIBLIOGRAPHY}

\section{Books}

Albus, James S. Brains, Behavior, and Robotics. Peterborough NH: BYTE Books, 1981.

Butler, Jr., A. G. Project Management Handbook. Edited by David I. Cleland and William R. King. New York: Von Nostrand Reinhold Company, 1983.

Clark, Charles T. and Lawrence L. Schkade. Statistical Analysis for Administrative Decisions. 2d ed. Cincinnati OH: South-Western Publishing Co., 1974.

Engelberger, Joseph F. Robots in Practice. New York: AMACOM, 1980.

Groover, Mikell P. Automation. Production Systems, and ComputerAided Manufacturing. Englewood Cliffs NJ: Prentice Hall, Inc., 1980.

Norusis, Marija J. SPSS/PC+ Statistical Package for the Social Sciences - Base Manual - V2.0. Chicago, IL: Privately Printed, 1988.

Reynolds, Henry T. The Analysis of Cross-Classifications. New York: The Free Press, 1977.

Society of Manufacturing Engineers. Industrial Robots. Dearborn MI: Society of Manufacturing Engineers, 1981.

\section{Articles}

Ackerman, Linda S. "Don't Fight Change, Guide It Instead." Qffice Administration and Automation XLV (July 1984): 26-65. 
Amram, Fred M. "Robotics: The Human Touch." Robotics Today (Winter 1981-1982): 12.

Argote, Linda; Paul S. Goodman; and David Schkade. "The Human Side of Robotics: How Workers React to a Robot." $\underline{\text { Sloan }}$ Management Review 24 (Spring 1983): 31-41.

Bickerstaffe, George. "Robotics: Managing the Change in Manufacturing." International Management 38 (March 1983): 20-24.

Bulkekey, William M. "Manufacturers Seek to Create More SafetyConscious Robots." The Wall Street Journal (4 October 1985): 23.

Burgert, Philip. "Robot Makers Looking for Better Markets." Manufacturing Week (May 1987): 5.

Byham, William C. "HRD and the Steel-Collar Worker." Training 21 (January 1984): 59-64.

Cathey, Paul. "Robots Will Change Managing From Shop Floor to CEO." Iron Age 225 (19 November 1982): 37-39.

Challis, Harry. "How Does AMT Affect the Worker." Production Engineer (February 1986): 20-22.

Chao, Georgia T. and Steve W. J. Kozlowski. "Employee Perceptions on the Implementation of Robotic Manufacturing Technology." Journal of Applied Psychology 71 (February 1986): 70-76.

Chase, Marilyn. "Robot Apprentices." The Wall Street Journal (10 November 1986): 16-18.

Craig, S. Russel. "Seeking Strategic Advantage with Technology? Focus on Customer Value!" Long Range Planning. 19 (April 1986): 50-56. 
Davidson, Jill E. "Tech Change: Boon or Bane for Professionals, Supervisors and Middle Managers." Canadian Public Administrator 29 (Winter 1986): 562-566.

Dilts, David M. and Grant W. Russell. "Accounting for the Factory of the Future." Management Accounting 66 (April 1985): 34-40.

Duncan, L. Scot. "Today's Investment Decisions - Tomorrow's Competitive Plants." Production Engineering (September 1985): $42-47$.

Foulkes, Fred K. and Jeffrey L. Hirsch. "People Make Robots Work." Harvard Business Review 62 (January-February 1984): 94102.

Goffee, Robert and Richard Scase. "Are the Rewards Worth the Effort? Changing Managerial Values in the 1980s." Personnel Review 15 (Winter 1986): 3-6.

Gorman, Robert. "Considerations for Selecting Robots." Robotics World 2 (August 15, 1984): 18-20.

Groves, Brenton R. "Why Robots Are Feared - Or Are They?" Engineers Australia 3 (October 19, 1984): 50-52.

Henderson, Bruce D. "The Logic of Kanban." The Journal of Business Strategy 6 (Winter 1986): 6-12.

Hinmon, Don L. "Automation Creates More Jobs Than it Displaces." Manufacturing Systems (Fall 1984): 48-49.

Hoard, Bruce. "Expert Advises Ways to Ease Robot Installation." Computerworld (March 15, 1982): 28.

Hollon, Charles J. and George N. Rogol "How Robotization Affects People." Business Horizons (May-June 1985): 74-80.

Jarosh, John I. "Prescription for Robotic Success: Right Job, Right Robot." Production 96 (November 1985): 68-70. 
Kakabadse, Andrew. "Politics of Planned Change." Industrial Management and Data Systems (September-October 1983):

Kerzner, Harold. "Project Management in the Year 2000." Journal of Systems Management 32 (October 1981): 26-31.

Knod, Jr., Edward M.; Jerry L. Wall; John P. Daniels; Hugh M. Shane; and Theodore A. Wernimont. "Robotics: Challenge for the Human Resources Manager." Business Horizons 27 (MarchApril 1984): 38-46.

Kochan, Anna. "Putting the U.S. Aerospace Industry on the Right Path." The FMS Magazine (July 1985): 140-143.

Krasnoff, Barbara. "Cinema Robots Clash with Reality." Robot/x News 1 (February 1983): 19.

Leap, Terry L. and Allayne B. Pizzolatto. "Robotics Technology: The Implications for Collective Bargaining and Labor Law." Labor Law Journal 34 (November 1983): 697-703.

Levitan, Sar A. and Clifford M. Johnson. "The Future of Work: Does it Belong to Us or to the Robots?" Monthly Labor Review 105 (September 1982): 10-14.

Liker, Jeffrey K.; David B.Roitman; and Ethel Roskies. "Changing Everything All at Once: Work Life and Technological Change." Sloan Management Review (Summer 1987): 29-47.

Lindorff, Dave. "Marketing Forecast, The Robot Revolution." Madison Avenue 26 (February 1984): 38-43.

Livingston, Willie C. "Modernization in Aerospace." Design News (8 July 1985): 61-66.

Longmire, Robert C. "Robots are Joining the Work Force." Production and Inventory Management Review and APICS News 2 (October 1982): 54-58. 
Lynn, Leonard. "Japanese Robotics: Challenge and-Limited-Exemplar." American Academy Political and Social Sciences Annals (November 1983): 16-27.

Maningas, Rick. "Remarks for Flexible Automation and Robotics." Production and Inventory Management Review and APICS News 3 (June 1983): 40-42.

Matherly, Timothy A. and Donna M. Matherly. "Employee Participation Eases the Transition to Office Automation." Journal of Systems Management (June 1983): 17-23.

McConkey, Dale and F. D. Barrett. "Managing in the Age the Robot." Business Quarterly 47 (February 1985): 40-46.

Myerson, Paul and Robert D. Hamilton III. "Matching Corporate Culture and Technology." Sam Advanced Management Journal 51 (Winter 1986): 8-13.

Nag, Amal. "Tricky Technology: Auto Makers Discover 'Factory of the Future' is Headache Just Now." The Wall Street Journal (13 May 1986): 1-12.

Norman, Colin. "The New Industrial Revolution." Futurist 15 (February 1981): 30-40.

Saga, Ichiro. "Japan's Robots Produce Problems for Workers." The Wall Street Journal (28 February 1983): 21.

Saleh, S. D. and Siva Pal. "Robotic Technology and Its Impact on Work Design and the Quality of Working Life." Industrial Management 27 (May-June 1985): 1-5.

Scarpello, Vida; William R. Boulton; and Charles W. Hofer. "Reintegrating R \& D into Business Strategy." The Journal of Business Strategy 6 (Spring 1986): 49-56.

Schoenfeldt, R. C. "The Foreman's Job as Perceived by His Wife." Supervisory Management (September 1980): 9-15. 
Skinner, Frank R. and Wesley J. Johnston. "Avoiding Robot Failures." Robotics Today (August 1985): 43-44.

Smith, Jr., Albert C. "Robotics: A Strategic Issue." SAM Advanced Management Journal 50 (Spring 1985): 7-12.

Soska, Geary V. and Carol F. Thompson. "Four-Phase Approach Assures Robot Success." Robotics World (July 1987): 23-25.

Tanner, Bill. "What Every Senior Manager Should Know About Robotics." Robotics World (19 July 1987): 26-27.

Tanner, William R. "Basics of Robotics." Industrial Robots (1981): 312.

Teresko, John. "Robots Come of Age." Industry Week 212 (25 January 1982): 35-42.

Trist, E. L. and K. W. Banforth. "Some Social Psychological Consequences of the Longwall Method of Coal-Getting." Human Relations (1951): 3-38.

Warner, Edward. "Attendees Blunt About Reason for Installing Robots." Computerworld 18 (11 June 1984): 11.

Warner, Edward. "GM Tells How Robot Became Team Player." Computerworld 18 (11 June 1984): 10.

Whaley, George L. "The Impact of Robotics Technology Upon Human Resources Management." Personnel Administrator 27 (September 1982): 61-71.

Wilson, Ian. "The Strategic Management of Technology: Corporate Fad of Strategic Necessity?" Long Range Planning 19 (April 1986): 21-22.

Wong, Jan; Stephen Kreider Joder; and Richard L. Hudson. "Robots: Next Step for Garment Makers." The Wall Street Journal (7 August 1986): 22. 
Woolley, Ewart. "Robots, Automation, and Spray Painting." Industrial Management and Data Systems (September-October 1983): 79.

Wyman, John. "SMS Forum: Technology Myopia - The Need to Think Strategically About Technology." Sloan Management Review 26 (Summer 1985): 59-64.

Yasaki, Edward K. "Japanese Push Robotics." Datamation 27 (July 1981): 56-61.

Zemke, Ron. "The Robots Are Coming! Training Tomorrow's High Tech Workers." Training 20 (June 1983): 18-31.

"1986 Industry Forecast." Robotics World (January 1986): 24-33.

"Distress Inevitable as Robots Replace Low End of Work Force." International Management 38 (July 1983): 3-7.

"How Popular are Robots With Their Co-Workers?" Management Review 72 (October 1983): 66-67.

"Newsbits - Robotics/Automation." Production 96 (November 1985): 17-19.

"Robotics on the Move in Small Parts Markets." Purchasing 93 (8 July 1982): 15 .

\section{Reports}

"Automated Machining Center." Production Technology Bulletin (8 February 1985): 3-4.

"Robotic Brush Deburring." Production Technology Bulletin (11 October 1984): 3-4.

"Vertical Fin Skin Robot," Production Technology Bulletin (9 March 1985): 3-4. 


\section{Publications of Learned Organizations}

Calis, Emily and Jeffrey G. Croll. "Robotics and Human Resource Development." In Robots 9 Conference Proceedings Held in Detroit._Michigan 2-6 June. 1985, Privately Printed, 1985.

Cox, John L. and J. Kent Butler. "Human Factors In Robotics: Physical, Mental, Safety, Legal." University of West Florida and Institute of Technology. Australia, 1984.

Fraser, Annette J. "Attitudes of Designers, Patternmakers and Production Managers as Related to Implementation of Computer Aided Design Systems in Apparel Production." Ph.D. diss., Texas Woman's University, 1984.

Krepps, Karen A. "The Effects of an Experimental Computer Training Program on Effective Job Responses for Employees Converting to an Automated Operation." Ph.D. diss., Wayne State University, 1986.

Loeffler, William R. "Human Factors Engineering and Robotics: Updating Quality of Work Life Models." In Robots 9 Conference Proceedings Held in Detroit. Michigan 2-6 June, 1985, Privately Printed, 1985.

Leutz, Walter Nordahl. "Aging and Technological Change: A Case Study of the U.S. Postal Service." Ph.D. diss., Brandeis University, 1981.

Miller, Mabry and Thomas J. Ault. "The Proactive Face of the Robotics Revolution: Managing the Human Factor." In Robots 9 Conference Proceedings Held in Detroit. Michigan 2-6 June, 1985, Privately Printed, 1985.

Newton, Robert E. "Retraining the Blue-Collar Worker for Robotics." In Robots 9 Conference Proceedings Held in Detroit. Michigan 2-6 June, 1985, Privately Printed, 1985.

Seitz, Dieter. "Automation, Employment and Qualification in Future Assembly - Some Results of a Representative Survey."In SME 
World Congress on the Human Aspects of Automation Held in Montreal. Canada 16-19 September 1984, Privately Printed,
1984 .

Stackpole, Peter T. "Factors Affecting Management's Resistance to Installation of a Robotics System." Technical Paper SME, Privately Printed, 1983.

Ulich, E. and F. Frei. "Industrial Robots: Threat or Aid to the Humanization of Work?" In Swiss Federal Institute of Technology. IFS Industrial Robots 14th International Symposium / Robot Technical Conference Held in Switzerland 2-4 October 1984, Privately Printed, 1985.

Weikle, Roger Dale. "The Attitude and Preferences of Local Union Leaders for Adjustment to Technological Change." Ph.D. diss., University of South Carolina, 1985.

"The Human Factor in Innovation and Productivity, Including an Analysis of Hearings on the Human Factor." HSE Committee on Science and Technology 97 Congress 2 Report By Don Fuqua, Chairman. Washington, D.C.: Government Printing Office, October 1982. 